\title{
Efficiency in university-industry collaboration: an analysis of UK higher education institutions
}

\author{
Alice Bertoletti ${ }^{1}$ (D) Geraint Johnes $^{2}$ \\ Received: 23 November 2020 / Accepted: 9 June 2021 / Published online: 1 July 2021 \\ (c) The Author(s) 2021
}

\begin{abstract}
We examine the determinants of university involvement in knowledge transfer activities, focusing on the value of external services provided by higher education institutions. Data come from 164 universities in the UK and are drawn from the HE Business and Community Interaction Survey (HE-BCI), with a variety of university- and region- specific explanatory variables grafted onto the data from other official sources. The production function for such external services is estimated using the appropriate stochastic frontier methods, and unobserved heterogeneity across institutions of higher education is accommodated by adopting a latent class framework for the modelling. We find strong effects of scale and of research orientation on the level of knowledge transfer. There are, however, two distinct latent classes of higher education institutions, and these differ especially in terms of how external service provision responds to subject specialization of universities and to economic conditions in the region. Research-intensive universities are concentrated in one of the latent classes and, in these institutions, the provision of external services appears to be highly efficient, while in the second latent class there is greater variation in the efficiency of universities.
\end{abstract}

Keywords University-industry collaboration · Efficiency $\cdot$ Stochastic frontier $\cdot$ Latent class

JEL classification I20 • O31

\section{Introduction}

The transfer of knowledge between universities and other actors in an economy-business, government, media and the public-is a core driver of innovation (Mueller, 2006). Once regarded as 'third mission' activity (the first two missions being teaching and research), knowledge transfer, engagement and impact have become central to the activities of higher

Alice Bertoletti

alice.bertoletti@polimi.it

Geraint Johnes

G.Johnes@1ancs.ac.uk

1 School of Management, Politecnico di Milano, 20156 Milan, Italy

2 Lancaster University, Lancaster LA1 4YX, UK 
education institutions (HEIs). During recent decades, HEIs around the world have substantially expanded their collaborations with business, responding to societal pressure to enhance their contributions to local and national economic development (Al-Tabbaa \& Ankrah, 2016). For instance, the European Patent Office (EPO) reports that patent applications from universities increased more than fivefold between 1992 and 2014, and a still faster growth rate is shown for joint applications with industry (Eurostat, 2020). Consistent with these data, the OECD reports that the share of businesses collaborating with HEIs has substantially grown in recent years, with an average share of around 14\% in 2016 (see Fig. 1).

This expansion in the engagement of universities with society has been encouraged by governments through financial and regulatory policy instruments. In 2017, around onequarter of OECD countries each spent over $€ 100$ million directly to support the development of collaborations between public research organisations and industry (OECD, 2019). Policy instruments have also fostered the diffusion of new intermediary organisations, such as business incubators, R\&D centres for science-industry collaboration and regional technology transfer organisations (OECD, 2019).

In this context, evaluating the performance of collaborations between universities and industry represents a priority for governments needing to provide evidence of the returns to their public investments (OECD, 2019). The present paper focuses specifically on the evaluation of efficiency in university-industry collaboration (UIC); we seek to establish the factors that influence the extent of such collaboration, and to identify players that are particularly successful in converting these factors into positive outcomes.

One of the key novelties of this paper relies on the indicator of UIC we employ. The literature on the efficiency in UIC focuses on patenting or licensing, exploiting the large availability of measures on intellectual property (IP). However, these activities represent just a limited aspect of UIC interactions and substantially differ from more common forms of collaborations, such as consultancy and contract research (D'Este \& Perkmann, 2011; Perkmann et al., 2013). For this reason, there is still limited understanding of efficiency-a concept that requires evaluation of both outputs and inputs-in university-industry collaboration from a wider

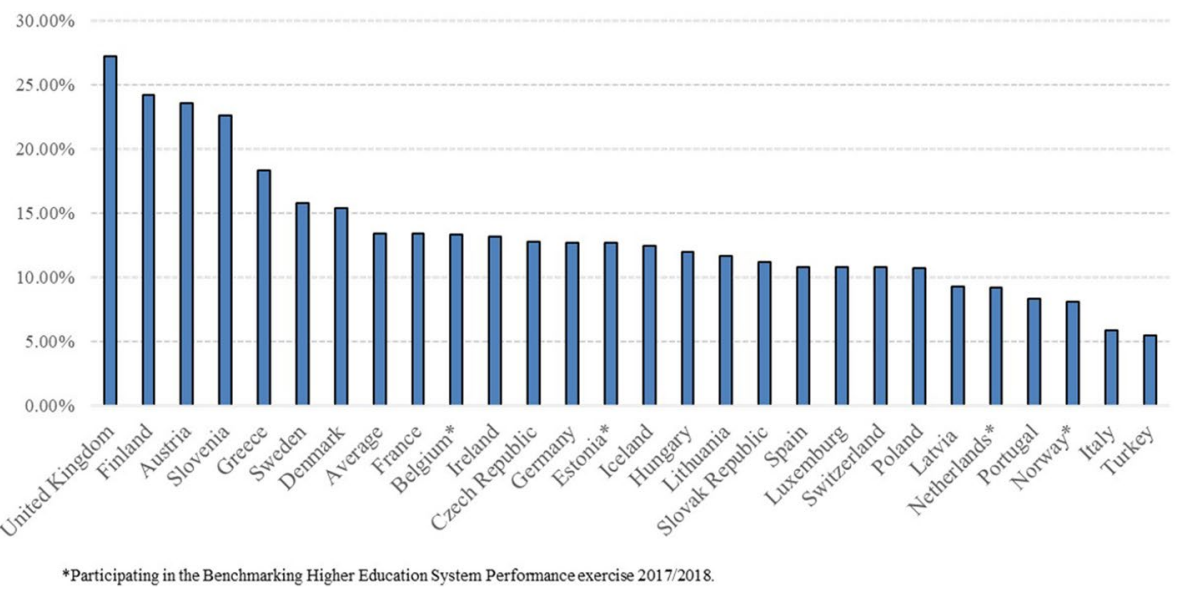

Fig. 1 Businesses collaborating on innovation with universities and other HEIs (2016). Note: data are expressed as a percentage of total enterprises with 10 or more employees. Source: OECD (2019) 
perspective. In this article, we address this issue by directly investigating research and consultancy contracts between universities and industry. More specifically, we aim at identifying and comparing the technical efficiency of universities in providing external services to companies, studying the main factors influencing these interactions. In this way, the paper contributes significantly to the extant literature. Indeed, although the efficiency of universities in providing contract research being scarcely investigated, these interactions generate the highest income among UIC activities (Perkmann et al., 2011).

Another main contribution of the paper relies on the methodological approach that we adopt. The UIC literature tends to employ a common model for describing the knowledge transfer of universities, without taking into account the unobserved heterogeneity of HEIs. On the other hand, the multi-product nature of universities has led to a specialisation of the higher education sector, where some institutions are more focused on teaching, some on academic research, and others in applied research and engagement (Hewitt-Dundas, 2012). It could therefore be the case that structural diversity of this kind defines different models of engagement between universities and industry. Our work addresses this issue, by employing a latent class framework for modelling the unobserved heterogeneity of HEIs, thereby providing an innovation to the literature in this field. In particular, we investigate whether it is appropriate to assume that a common model can describe university engagement with industry or whether, on the contrary, the heterogeneity of HEIs defines typologies of universities responding differently to the determinants of UIC.

We analyse data on 164 universities in the UK. Of all the OECD countries, the UK has the largest share (more than 25\%) of businesses collaborating with universities (see Fig. 1). Two recent policy initiatives support this. First, since 2003, the Knowledge Transfer Partnerships (KTP) programme has promoted collaboration between universities and firms by providing a platform through which companies and graduates are encouraged to interact and collaborate. Secondly, from 2014, the Research Excellence Framework (REF)-which, as a means of informing funding settlements, evaluates research undertaken in university departments-has started for the first time to include the economic and social impact of research as an output measure. This initiative has encouraged HEIs to intensify their connection with business, specifically through transfer of research outcomes to industry. In 2014, the initiative led to the submission of almost 7000 impact case studies by 154 UK universities. At the same time, research councils have required applicants for funding to produce impact statements describing how they intend to optimise the wider social and economic influence of their work.

The paper is structured as follows. "Literature" section contains a review of the key literature examining the channels and the determinants of university-industry collaboration. "Data" section presents the data and the variables we include in the empirical model, which is described together with the methodological approach in "Methodology" section. "Results" section contains the main findings, which are then discussed, along with their contributions to research and the policy implications. "Conclusion" section concludes the paper.

\section{Literature}

University-industry collaboration refers to the interactions between industry and any part of the higher education system involving knowledge or technology transfer (Bekkers \& Bodas Freitas, 2008; Siegel et al., 2003). The literature dealing with this topic is particularly extensive and provides different classifications of the interactions between universities and industry (see among others Ankrah et al., 2013; Santoro \& 
Gopalakrishnan, 2000; Bonaccorsi \& Piccaluga, 1994; Fernandez-Esquinas et al., 2016). The systematic literature review presented in the paper of Ankrah and AL-Tabaa (2015) summarises different categories of interaction identified in the literature, providing a single classification. The authors define six main groups based on the framework proposed by Bonaccorsi and Pittaluga (1994): (1) personal informal relationships (e.g. academic spin-offs and individual consultancy); (2) personal formal relationships (e.g. student internships and fellowships); (3) third party (e.g. institutional consultancy and government agencies); (4) formal targeted agreements (e.g. contract research, patenting and licencing agreements); (5) formal non-targeted agreements (e.g. research grants and broad agreements); (6) focused structures (e.g. innovation centres and association contracts). The six groups differ from each other in terms of resource involvement, degree of formalisation and length of the agreement.

Based on this classification, our paper is mainly focused on the formal activities surrounding targeted agreements and, in particular, on contract research, which identifies university-industry collaborations formalised through research and services contracts. It is worth specifying that contract research significantly differs from intellectual property agreements-though the latter are defined as targeted agreements activities as well. Contrary to licensing and patenting, contract research is not primarily driven by commercial reasons, but it is rather motivated by research-related advantages (D'Este \& Perkmann, 2011). Indeed, these interactions contribute significantly to research and R\&D activities (Roessner and Bean, 1993; D’Este \& Perkmann, 2011), while intellectual property agreements typically generate more modest knowledge transfer (Agrawal \& Henderson, 2002). Moreover, the two forms of knowledge transfer differ in the role played by industry. While the firm represents only the final user during patenting and licencing activities, it usually collaborates more organically with universities when forms of academic engagement are developed (Perkmann et al., 2013).

Generally, studies in the field of efficiency in university-industry collaboration focus on the licencing or patenting activities of higher education systems. For instance, Thursby and Kemp (2002) have studied efficiency in the licencing activities of US universities by employing a data envelopment analysis (DEA) approach. The results reveal substantial inefficiency among universities, which the authors attribute to universities specialising in activities other than licencing, notably research and teaching. On the contrary, the results presented by Anderson et al. (2007) have detected high levels of efficiency associated with US leading universities, in terms of start-up creation, licencing and patenting activities. The efficiency of licencing activity in US universities has been studied also by Ho et al. (2014), who have divided the efficiency process into the stages of 'research innovation' and 'value creation'. The results, based on a two-stage process DEA, show that universities that attain high efficiency scores typically do so only in one of the two stages.

Exploiting the measurable nature of IP, the literature has focused on efficiency in the commercialisation of academic knowledge, rather than more collaborative forms of knowledge transfer. However, it is worth noting that these activities represent just one part of the entirety of university-industry collaboration (D'Este \& Perkmann, 2011; D'Este \& Patel, 2007). Among all the typologies of interactions between universities and industry in the $\mathrm{UK}$, the highest income is generated by contract research, while intellectual property represents the smallest part of value (Perkmann et al., 2011). The two forms of interaction are structurally different, and findings of studies aimed at explaining such activity may considerably vary between commercialisation and contract research. Therefore, in examining the literature studying the factors that influence UIC, these differences should be taken into account. 
Firstly, academic discipline seems to play a relevant role in affecting the intensity, regardless of the forms of relationships between industry and universities (see Bekkers \& Bodas Freitas, 2008; Landry et al., 2007). In stark contrast, the type of industrial activities pursued by the business partner seems not to represent a relevant determinant of UIC (Bekkers \& Bodas Freitas, 2008). Applied science disciplines, such as engineering, are more likely than others to establish relationships with businesses and industrial companies (Bozeman \& Gaughan, 2007). In the case of contract research, the activities have an applied nature, since they are usually explicitly commissioned by companies (Van Looy et al., 2004). Engineering and biology seem to foster also a high level of efficiency in licencing activity, thanks to their high market orientation (Thursby \& Kemp, 2002), while medical schools are usually associated with low efficiency in their technology transfer (Thursby \& Kemp, 2002; Anderson et. al., 2007). By way of contrast, skills and knowledge in the field of social sciences are more likely to be transferred through personal contracts or labour mobility (Perkmann et al., 2013).

The literature has focused also on the role of the university's geographical proximity to businesses or industrial districts. Analysing the presence of collaborative projects between universities and industry in Algeria, Boutifour et al. (2015) have found that businesses are more likely to interact with universities if they are operating in the same geographical area. Meanwhile, the study of UK universities provided by D'este and Patel (2007) points out that the effect of geographical proximity depends on the characteristics of the industry clusters, but it does not depend on to the form of university-industry collaboration. To be specific, geographical proximity is not relevant in the case of dense clusters of technology-intensive businesses. This is partially confirmed by Hewitt-Dundas (2012), who found that the distance between businesses and universities is not a significant determinant of the intensity of academic cooperation with industry in the UK. It may be the case that proximity is less important either where quality differences across universities are very apparent or where the novelty of technology means that few centres of excellence have developed in the higher education system.

Research-intensive universities typically show a great ability to undertake collaborative projects with companies, compared to less research-oriented institutions (Laursen et al., 2011; Hewitt-Dundas, 2012; Ray, 2017). Research performance of these universities may, in fact, reflect their ability to engage in knowledge transfer (Hewitt-Dundas, 2012). Moreover, in the long term, a virtuous circle can be established, since high research intensity supports greater UIC that, in turn, fosters research output and funding (Sengupta \& Ray, 2017). On the other hand, Perkmannet al. (2011) suggest that the positive link between research quality and academic engagement holds only for specific disciplines. Concerning the transfer of intellectual property from HEIs to industry, research performance seems strongly and positively to influence these activities (O'shea et al., 2005; Perkmann et al., 2013). Following the results of Anderson et al. (2007), research-intensive universities are also more efficient than others in managing their licencing activities. However Thursby and Kemp (2002) detect the highest levels of intellectual property efficiency amongst US universities with low research quality, ascribing this behaviour to the specialisation of highquality scholars in basic, rather than applied, research. ${ }^{1}$

Size may also be an important factor. Ho et al. (2014) found that large universities in the US are more likely to be efficient in their intellectual property activities since these are well

\footnotetext{
${ }^{1}$ The University of Florida's earnings from the Gatorade patent are well known (Grassmuck, 1991).
} 
resourced. The positive effect of university dimension is not always confirmed, however, as a relevant determinant of academic licencing (see Thursby \& Kemp, 2002). Other relevant factors influencing intellectual property are the age of the university, with a negative effect (Azagra-Caro et al., 2006), and the funding model, with private universities being incentivised to perform better in knowledge transfer than public ones (Thursby \& Kemp, 2002).

The presence of a strong organisational structure may positively influence the ability of universities to undertake IP agreements. Indeed, the commercialisation of academic knowledge depends on the central support the university can offer. Instead, individual characteristics are more relevant for contract research, since it is usually driven by small research groups or single researchers (Perkmann et al., 2013). Among the personal characteristics, academic seniority and the research productivity of scholars seem to play a relevant role in fostering academic engagement (Gulbrandsen \& Smeby, 2005; Haeussler \& Colyvas, 2011). Licensing and patenting seem, instead, to be more influenced by cultural factors. Studying patenting activity in the US, Siegel et al. (2003) found that cultural barriers have substantially affected the technology transfer of universities, while highly competitive academic contexts tend to foster the commercialisation of university inventions (Goldfarb \& Henrekson, 2003).

The analysis of the literature presented here offers an overview of the factors that are likely to influence university-industry collaboration, shedding light on the differences between IP and contract research. Based on these differences, the findings on the efficiency of universities in licencing activities cannot be extended to other forms of UIC (Perkmann et al., 2013). In this way, the review highlights the importance of broadening the focus of efficiency analysis from the commercialisation of academic knowledge to include the less investigated forms of academic engagement, and in particular contract research.

A further deficiency of the available literature concerns the lack of studies considering the role of HEI heterogeneity in affecting university-industry collaboration. The literature assumes the existence of a common model for describing the knowledge transfer of HEIs, which does not depend on the characteristics and the specialisation of universities. Considering, however, the high diversity among higher education institutions, this assumption could be too restrictive or even unrealistic, leading to questionable results.

By addressing these gaps, our paper studies the contract research and consultancy services provided by universities, by taking into account the unobserved heterogeneity of institutions and seeking to identify typologies of HEIs based on how they respond to the determinants of UIC.

\section{Data}

Our data concern the 2017-18 academic year and come from several sources (see Table 1). The Higher Education Statistics Agency (HESA) provides a wealth of data about universities in the UK. HESA's HE Business and Community Interaction Survey (HE-BCI), which has been running annually since 1999 , offers information about a wide range of third mission activities, including patents, licences, spin-offs, start-ups, consultancy activities, executive education, public lectures, exhibitions and other events. The dependent variable used in our analysis, the total value of external services provided by universities, comes from this source. In particular, we focus on the income associated with consultancy and contract research. The amount generated by these interactions represents more than $50 \%$ of the total income generated by knowledge transfer of UK universities in 2017/18 (see Table 2). In 


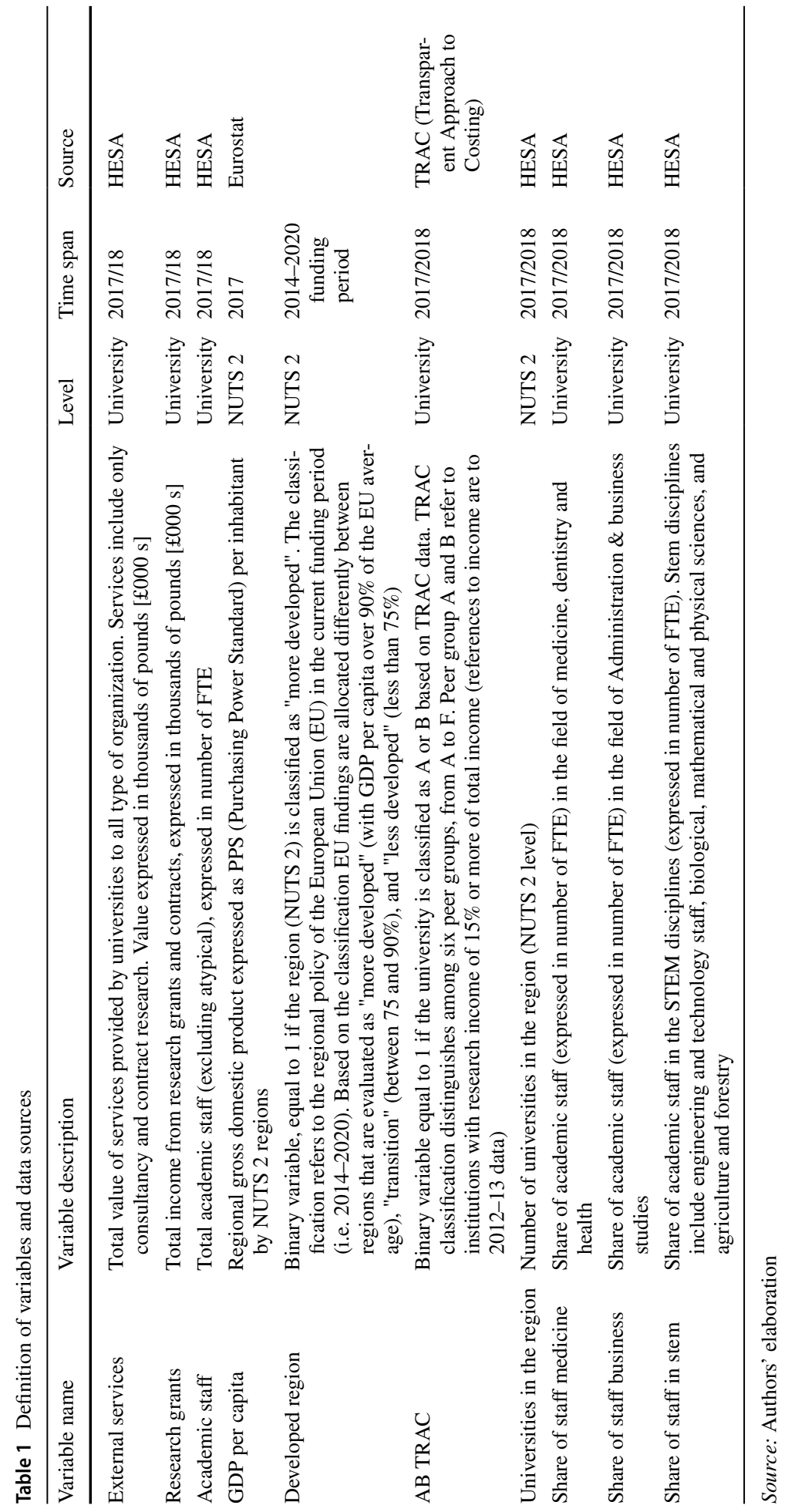


addition, the table confirms the main findings in the literature, showing that intellectual property agreements generate the lowest value among all the interactions (i.e. 6,6\%).

The HE-BCI is currently undergoing review; with changes likely to the structure of the survey, this is a particularly good time to use data for which an uninterrupted series is available. $^{2}$

Other HESA datasets, focused on students, staff and finances of higher education institutions, provide the data source for many of the explanatory variables used in our study. In particular, we use data on total staff numbers and also on staff in specific academic disciplines, available from HESA's staff record, and we use data on total income from research grants as a measure of research intensity, provided by HESA's finance record. Other characteristics of universities are taken into account by including information on the TRAC (Transparent Approach to Costing) classification of universities, identifying six peer groups of institutions. We focus the attention on peer groups A and B which refer to institutions whose research income represents $15 \%$ or more of their total income.

The economic environment in the regions (NUTS2) within which each university operates is likely to be an important factor in determining the extent of interaction between HEIs and business. Regional data on GDP per capita come from Eurostat and refer to NUTS2 level regions. A further candidate explanatory variable concerns the eligibility of the region within which the HEI is located for EU structural and investment funds (i.e. EU Regional Policy 2014/2020). Such funds may directly promote university-business collaboration. But at the same time the eligibility of a region likely reflects the poverty of existing innovation infrastructure, and so regions qualifying for structural funds may be disadvantaged in their ability to transfer knowledge successfully between HEIs and business. The detailed definitions of the variables employed in the empirical analysis appear in Table 1, while descriptive statistics appear in Table 3.

The number of observations represents the total number of UK universities for which data are provided by HESA, namely 164 HEIs. UK universities differ widely in their reports of the value of external services provided to businesses, ranging from a maximum of $£ 186.3$ million, generated by Oxford University, to null values, registered mainly by some specialist art institutes (e.g. Courtauld Institute of Art and the National Film and Television School). Besides Oxford, particularly high levels of external services are provided by the Imperial College of Science, Technology and Medicine and by University College London, respectively with $£ 114.5$ million and $£ 87.1$ million in $2017 / 2018$. The kernel density of the values of external services and their logarithm are represented, respectively, in Fig. 2 and Fig. 3. The plots highlight that most universities generate relatively low income from their interactions with businesses, with very few institutions exceeding $£ 20$ million. In particular, the kernel density of external services follows a logarithmic distribution (see Fig. 2 and Fig. 3).

The universities reporting high levels in the values of external services generally have strong research orientation and hence report high incomes from research grants and contracts. For example, research grants and contracts contribute some $£ 579$ million to the budget of Oxford University; and Cambridge University has a research income of some $£ 524.9$ million. External services and research grants are related also to the size of the universities-larger universities usually present higher values in both research grants and external services (see Table 4).

\footnotetext{
${ }^{2}$ While we use data only for a single year, the long history of data collection is important, not least because early attempts to collate data on third mission activities were plagued with measurement problems.
} 


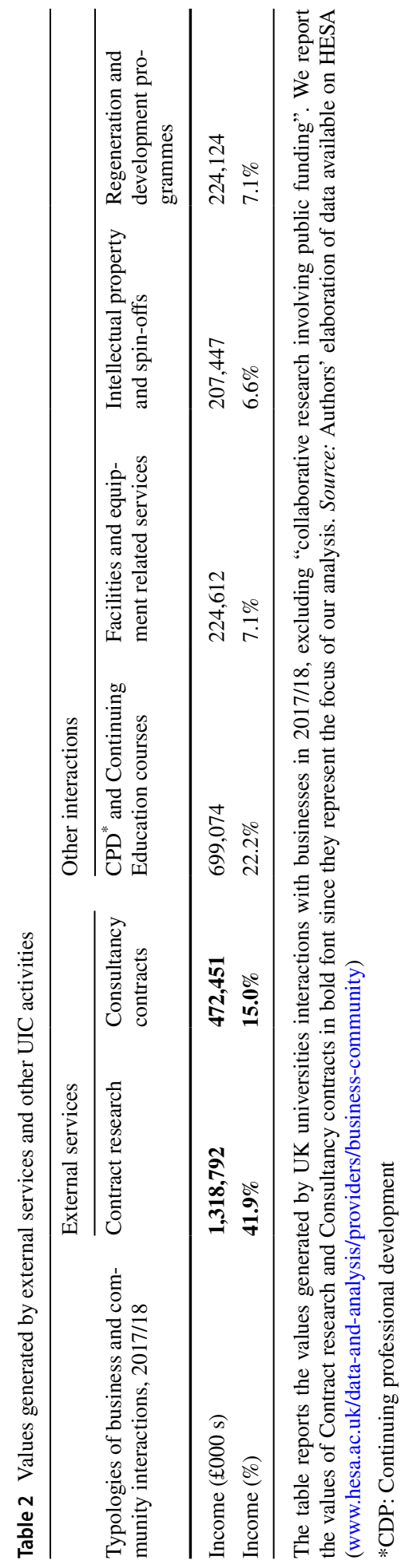


Table 3 Descriptive statistics of the main variables included in the analysis

\begin{tabular}{llllll}
\hline Variable & Obs. & Mean & Std. Dev. & Min & Max \\
\hline External services & 164 & $11,045.54$ & $22,804.12$ & 0 & 186,316 \\
Academic staff & 163 & 1050.767 & 1176.791 & 25 & 6700 \\
Research grants & 163 & $38,183.88$ & $88,125.18$ & 0 & 579,036 \\
Developed region & 164 & 0.798781 & 0.40214 & 0 & 1 \\
GDP per capita & 164 & $50,882.32$ & $54,571.92$ & 19,700 & 188,000 \\
Universities in the region & 164 & 7.804878 & 6.583003 & 1 & 22 \\
Share of staff in stem & 163 & 0.23268 & 0.202973 & 0 & 1 \\
Share of staff business & 163 & 0.091509 & 0.104086 & 0 & 0.952381 \\
AB TRAC & 164 & 0.341463 & 0.475653 & 0 & 1 \\
\hline
\end{tabular}

Source: Authors' elaboration using Stata 14

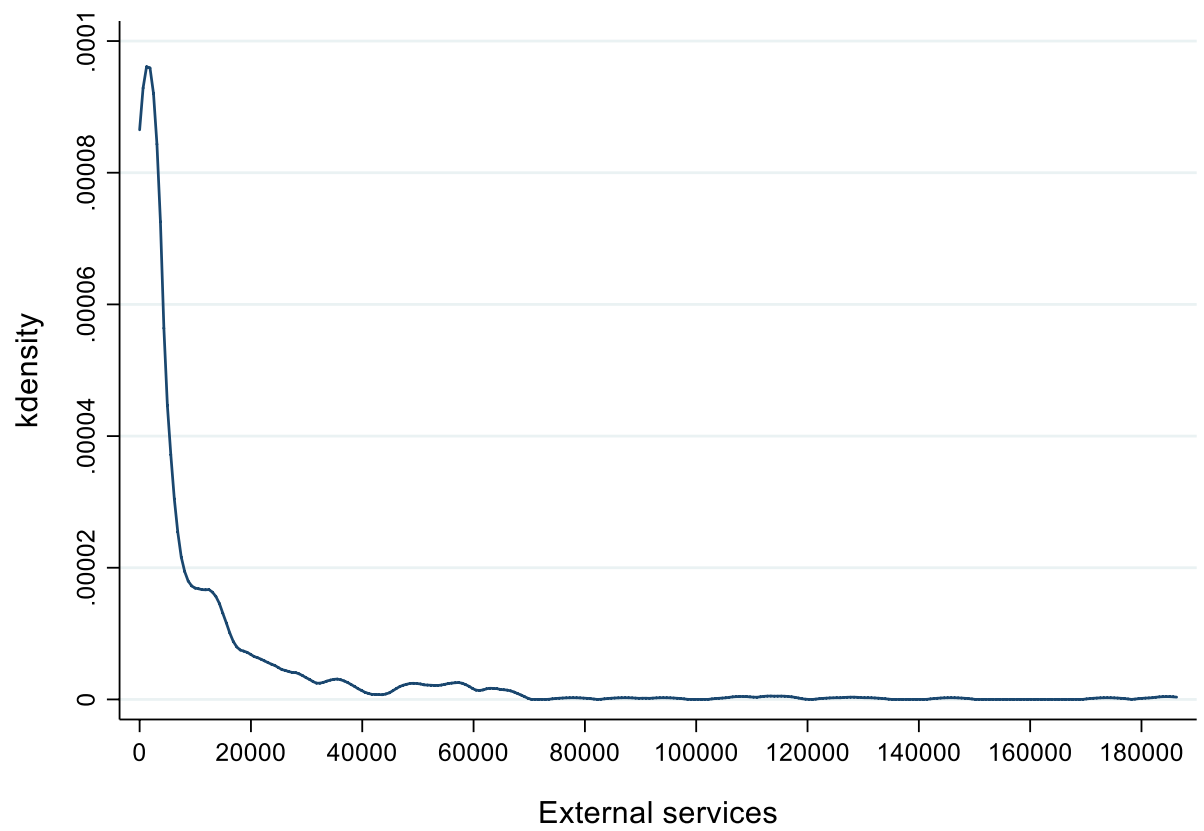

Fig. 2 Kernel density of external services values. Source: Authors' elaboration using Stata 14

Analysis of the composition of the academic staff of universities reveals that, on average, $23.27 \%$ work in STEM disciplines. ${ }^{3}$ Some universities are entirely specialised in medical disciplines ${ }^{4}$ (i.e. all staff work in this field); this is the case of Liverpool School of Tropical Medicine and the University College of Osteopathy.

\footnotetext{
3 Stem disciplines include engineering and technology staff, biological, mathematical and physical sciences, and agriculture and forestry.

${ }^{4}$ i.e. medicine, dentistry and health disciplines. 


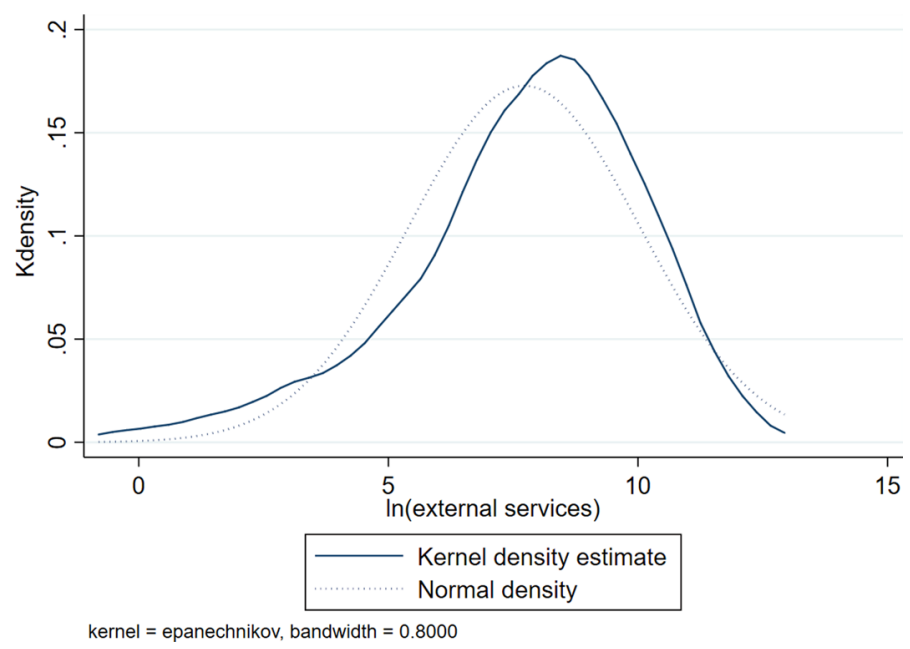

Fig. 3 Kernel density of the logarithms of external services values. Source: Authors' elaboration using Stata 14

Analysing data on the share of staff working in business and administration, only two universities report percentages over 25\%: London Business School, with a share of 95,24\%, and University College Birmingham, with a share of 69,09\%.

Analysis of the economic environment of the (NUTS2) regions in which universities operate reveals significant disparities among the geographical areas (see the maps in Fig. 4). As might be expected, there are marked differences between the core and periphery, though this is not uniform; within Scotland, for example, the central belt and east coast is relatively highly developed, the area surrounding Aberdeen in particular having benefitted from offshore extraction of natural resources. In terms of GDP per capita, the richest UK region in 2017 is West Inner London, with almost $£ 190,000$ per inhabitant, considerably higher than the second richest region, East Inner London, which registers $£ 50,500$ per capita. ${ }^{5}$ The poorest regions are Cornwall and West Wales respectively, with $£ 20,300$ and $£ 19,700$ per inhabitant. The map on the right side of Fig. 4 represents the division between the 'more developed' regions (Objective 3 of the EU Regional Policy) and the 'transition' or 'less developed' regions ${ }^{6}$ (Objectives 1 and 2 of the EU Regional Policy). Transition and less developed regions are those receiving the most subsidy from Europe: for 2014-2020, around $€ 5.1$ billion were allocated for the $12 \mathrm{UK}$ regions belonging to these categories. The funds are designed to be invested for achieving the priorities defined for the funding period, such as promoting the research investment of the UK business sector and improving educational policies. As represented in the maps of Fig. 4, the division among the three EU objectives reflects the GDP per capita of the territory. The regions that benefit more from EU subsidies are the ones with lower GDP per capita (see the definition in Table 1).

\footnotetext{
5 According to NUTS 2 classification, the area of London is divided into two regions: West Inner London (UKI3) and East Inner London (UKI4). In Table 9 of the Appendix, we repeated the analyses considering London as one aggregated region since it refers to one geographical market. The robustness check does not highlight remarkably differences compared to the analyses presented in the main body of the paper.

6 We aggregated Object 2 and Objective 1 since only two regions in the UK are classified as 'less developed', i.e. Cornwall and the Isles of Scilly, and West Wales and the Valleys.
} 


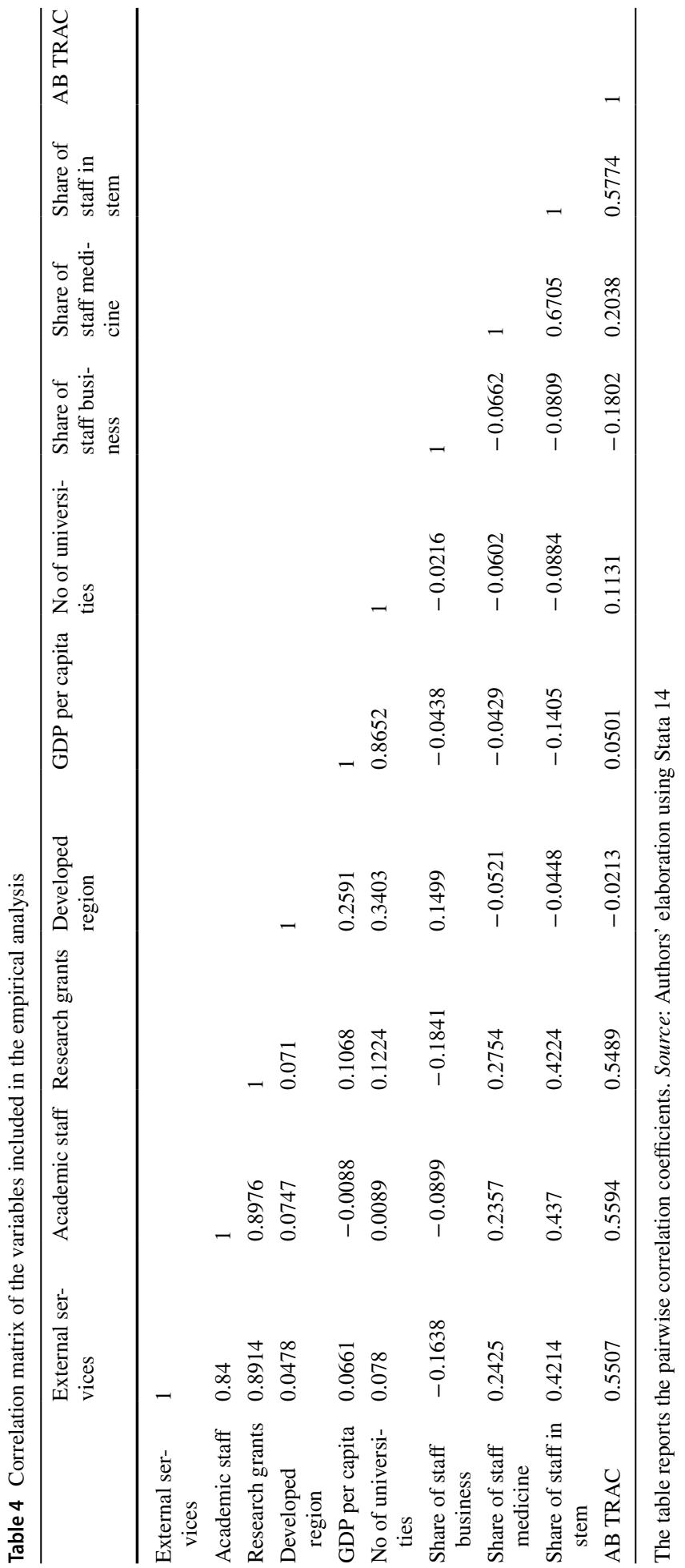




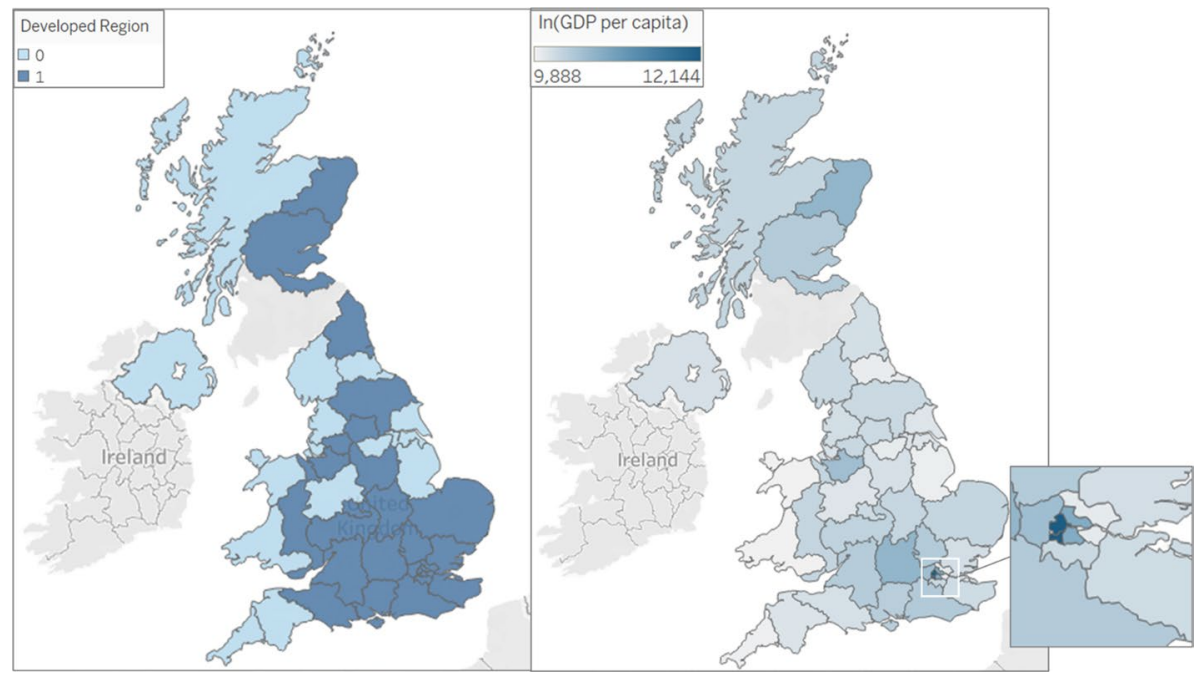

Fig. 4 Characteristics of UK regions. Note: the map on the left side of the picture shows the division between developed regions (dark colour) and the not-developed/transition regions (light colour); the map on the right reports the natural logarithm of the GDP per capita. Source: Authors' elaboration using Tableau Public

The GDP per capita of the region is also positively correlated with the number of universities within its territory, as shown by the correlation matrix in Table 3.

\section{Methodology}

In seeking to identify the determinants of knowledge transfer, we analyse the data by employing a latent class stochastic frontier model (LCSFM). The main benefit of using a stochastic frontier approach is that it allows us to access the tools of statistical inference, and does not (like some other types of frontier estimation) give arguably undue weight to outlying observations. For this reason, in the case of our analysis, this approach is preferable to non-parametric techniques, such as data envelopment analysis. More specifically, LCSFM explains our dependent variable, while at the same time allowing for both unobserved heterogeneity across institutions and variation in technical efficiency across HEIs. This methodological strategy is central for the purpose of the research since higher education (especially in the UK) is characterised by considerable heterogeneity (Johnes \& Johnes, 2009). The use of frontier models controlling for heterogeneity has now become standard in the literature dealing with the efficiency of universities (see, for example, Agasisti \& Gralka, 2019; Johnes et al., 2008; Johnes \& Salas-Velasco, 2007; Laureti, et al., 2014). However, the application of frontier models accommodating unobserved heterogeneity is still unusual in the context of universitybusiness interaction and is an important innovation of the present paper.

The latent class stochastic frontier model is based on the traditional production frontier model, as expressed by Aigner et al. (1977): 


$$
y=f(x) \exp (\varepsilon) ; \quad \varepsilon=v-u
$$

where $y$ is the output, $x$ the vector of the inputs, $f(x)$ denotes the technology and $\varepsilon$ is the error term, which in turn is composed of two components. The symmetric component $v$ represents the normally distributed residual that should capture the usual statistical noise; meanwhile $u$ is a non-negative, and asymmetric, residual that is supposed to capture technical inefficiency. The $u$ term is assumed to follow a one-sided distribution, which must be specified a priori.

A variety of formulations of equation 1 has been presented in the literature in order to control for the potential heterogeneity among observations. One possible approach is the random parameters model (RPM), proposed by Greene (2005). This method allows estimation of a distinct production functions for each university by considering a vector of coefficients that is allowed to vary randomly (according to a specified distribution) across institutions. Alternative approaches are based on a classification of the sample that generates several groups, for which different production functions are estimated. The classification of the sample can base on a priori characteristics (e.g. Battese et al., 2004; Newman $\&$ Matthews, 2006) or on clustering techniques (Maudos et al., 2002). However, there is an increasing interest on the latent class approach to determine groups of observations with common characteristics (see, for instance, Agasisti \& Johnes, 2015; Sauer \& Paul, 2013; Greene, 2005). These models, known as latent class stochastic frontier models, allow prediction of the probabilities of class membership based on maximum likelihood. The class probabilities are estimated simultaneously with the production frontier, determining therefore a one-stage procedure. For this reason, LCSFM may be considered a good method for the estimation of production functions that accommodate inefficiency in the presence of unobserved heterogeneity. As argued by Orea and Kumbhakar (2004), in LCSFM the class probabilities are a priori different from zero, allowing all the observations to be used in estimating the technological structure. Unlike the random parameters approach, the latent class frontier model can be used with cross-section data, and does not require use of a panel.

In a LCSFM, equation 1 assumes the following form:

$$
y_{i}=\left.f\left(x_{i}\right)\right|_{j} \exp \left(\left.v_{i}\right|_{j}-\left.u_{i}\right|_{j}\right)
$$

where $i$ identifies the university and $j$ denotes the latent class. ${ }^{7}$ Therefore, the likelihood function (LF) for each university is the weighted sum of its LF for each class $\mathrm{j}$-using as weights the prior probabilities of class j membership (Greene, 2005).

$$
L F_{i}=\sum_{j} P_{i j} L F_{i j}
$$

The prior probabilities $P_{i j}$ must satisfy the following two conditions:

$$
\left\{\begin{array}{l}
0 \leq P_{i j} \leq 1 \\
\sum_{j} P_{i j}=1
\end{array}\right.
$$

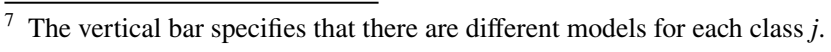


For this reason, prior probabilities are usually parametrised as a multinomial logit model:

$$
P_{i j}=\frac{\exp \left(\delta_{j} q_{i}\right)}{\sum_{j} \exp \left(\delta_{j} q_{i}\right)}
$$

where $q_{i}$ is the vector of university-specific characteristics that identify the probabilities of class membership, called 'separating variables'; while, $\delta_{j}$ denotes the parameters of the model to be estimated for each class (with one group chosen as a reference in the multinomial logit).

The LCSFM allows identification of the most suitable number of classes by providing useful information criteria. In particular, the number of classes used for our empirical estimations has been identified based on Schwarz's Bayesian information criterion (BIC) and the Akaike Information Criterion (AIC), defined as:

$$
\begin{gathered}
\mathrm{BIC}=\log (n) \cdot k-2 \log \mathrm{LF}(j) \\
\mathrm{AIC}=2 k-\log \mathrm{LF}(J)
\end{gathered}
$$

where $k$ is the number of model parameters, $\operatorname{LF}(J)$ is the value of the likelihood function for the $J$ th group and $\mathrm{n}$ is the number of observations. The preferred model is the one that reports the lowest value of BIC and AIC.

\section{Results}

\section{Regressions and stochastic frontier model estimates}

As a first step, we analysed the determinants of university-industry collaboration by performing a regression analysis. Table 5 reports the results of 11 models that gradually include all the regressors we presented in "Methodology" section. The number of academic staff and research funding stand out as the main factors fostering UIC, with large and statistically significant coefficients. On average, a $10 \%$ increase in the number of academic staff can generate a growth of $9.2 \%$ in the value of external services. Meanwhile with a rise of $10 \%$ in the research income, universities can increase their external services by an amount that varies from $3.6 \%$ (model R11) to 5\% (model R2). Another important determinant of UIC is subject specialization. Universities that focus more on STEM disciplines seem to generate higher values from their external services (see model R6, R8, R10 and R11 in Table 5). Positive effects have been also found for universities with a high share of academic staff in medicine and healthcare (see model R9, R10 and R11 in Table 5). On the contrary, institutions specialising in business and administration subjects seem to be at a disadvantage in providing external services (see model R7, R8, R10 and R11 in Table 4). Finally, 'more developed' regions, the ones receiving lower funding from the regional policy of the European Union, seem to be associated with lower values of external services, though the effect is not strongly statistically significant.

Adopting a stochastic frontier framework, we have re-estimated the main models of Table 5 controlling for the potential inefficiency of universities in providing external 


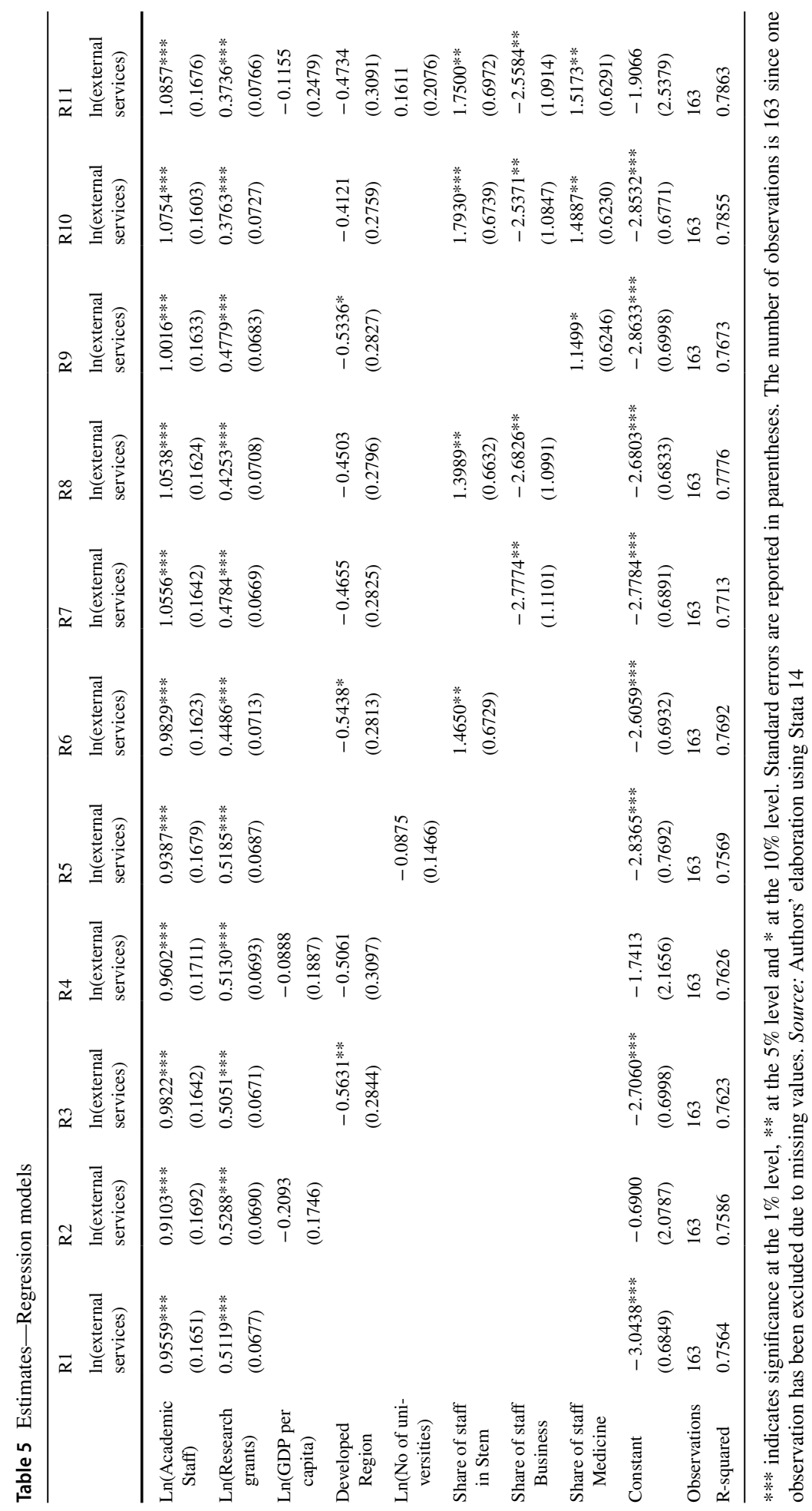




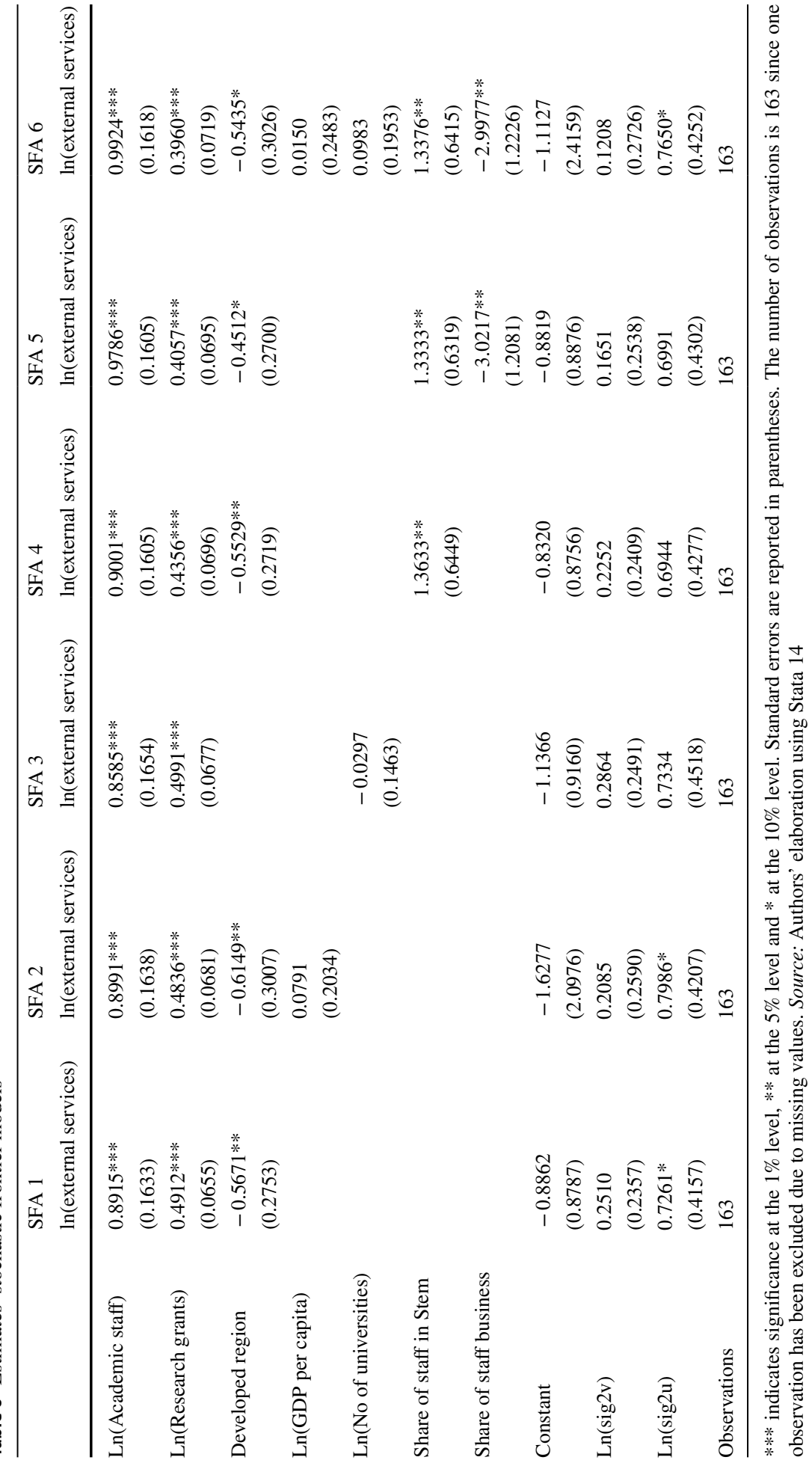


services. The estimates are reported in Table 6; the values of the coefficients do not, generally speaking, differ much from those obtained in the OLS regressions of Table $5 .^{8}$

A particularly appealing feature of the stochastic frontier approach is that it allows us to estimate the technical efficiency of HEIs as producers of business interaction. In detail, the efficiency scores associated with the full model (SFA7) suggest that specialised institutions, in particular the art and music institutions, tend to be amongst the most efficient universities (see Table 10 in the Appendix, for further detail). However, this observation in itself suggests that heterogeneity across universities is not sufficiently captured by variation in the explanatory variables, and we should therefore use an estimating strategy that admits the possibility of unobserved heterogeneity. In other words, the general hypothesis of having a single production function for all UK universities seems to be too restrictive for our analysis. For this reason, we estimate a latent class stochastic frontier model (LCSFM) and report the results in the next paragraph.

\section{Latent class stochastic frontier model estimates}

We estimated the LCSFM by maximum likelihood and employing AB TRAC as separating variable. Alternative specifications on separating variables have been tried but have not been reported since they generate qualitatively similar results. ${ }^{9}$ Based on BIC (Bayesian Information Criterion) and AIC (Akaike Information Criterion) statistics, we set the number of classes equal to two. The model with two classes has indeed the lowest BIC statistic, equal to 576.75, and presents also a low value of AIC, equal to 508.68 (see Table 11 in the Appendix, for more details).

Table 7 reports the coefficients of LCSFM models estimated for the two groups. The table reports five models that gradually include all the independent variables presented in "Data" section. The estimates are not directly comparable among models since the definition of the two latent classes varies for each model. In fact, the definition of the classes is based not only on the separating variable (that remains the same for each model), but also on the specification of the production function. This is related to the single-stage approach that simultaneously estimates the coefficients of the production function and the composition of the classes. Even if the composition of the classes is different among models, in all columns of Table 6, class 2 tends to represent the research-intensive universities. On the contrary, class 1 generally identifies the universities that are less likely to be classified as type A or B, according to TRAC definition.

Taking as a reference the full model (LCSFM 5), Table 8 provides the descriptive statistics for class 1 and class 2, while the complete list of universities belonging to each class is reported in Table 12, in the Appendix. The definition of the classes is primarily based on the separating variable AB TRAC and, in fact, $90 \%$ of observations in class 2 belong to the TRAC groups A or B, while members of these groups comprise only $1.9 \%$ of observations in class 1 . Class 1 is the larger group with $63.2 \%$ of the observations and differs from class 2 primarily in terms of research grants, academic staff and values of external services.

\footnotetext{
8 The stochastic frontier models do not include among the regressors the share of staff in medical disciplines since the models fail to converge when this variable is included. This could be due to the high correlation between the share of staff in medical disciplines and the share of staff in STEM disciplines (see Table 4).

9 To be specific, we tested the model also using two separating variables, namely AB TRAC and share of staff in STEM. Moreover, we performed the estimations without specifying any separating variable.
} 


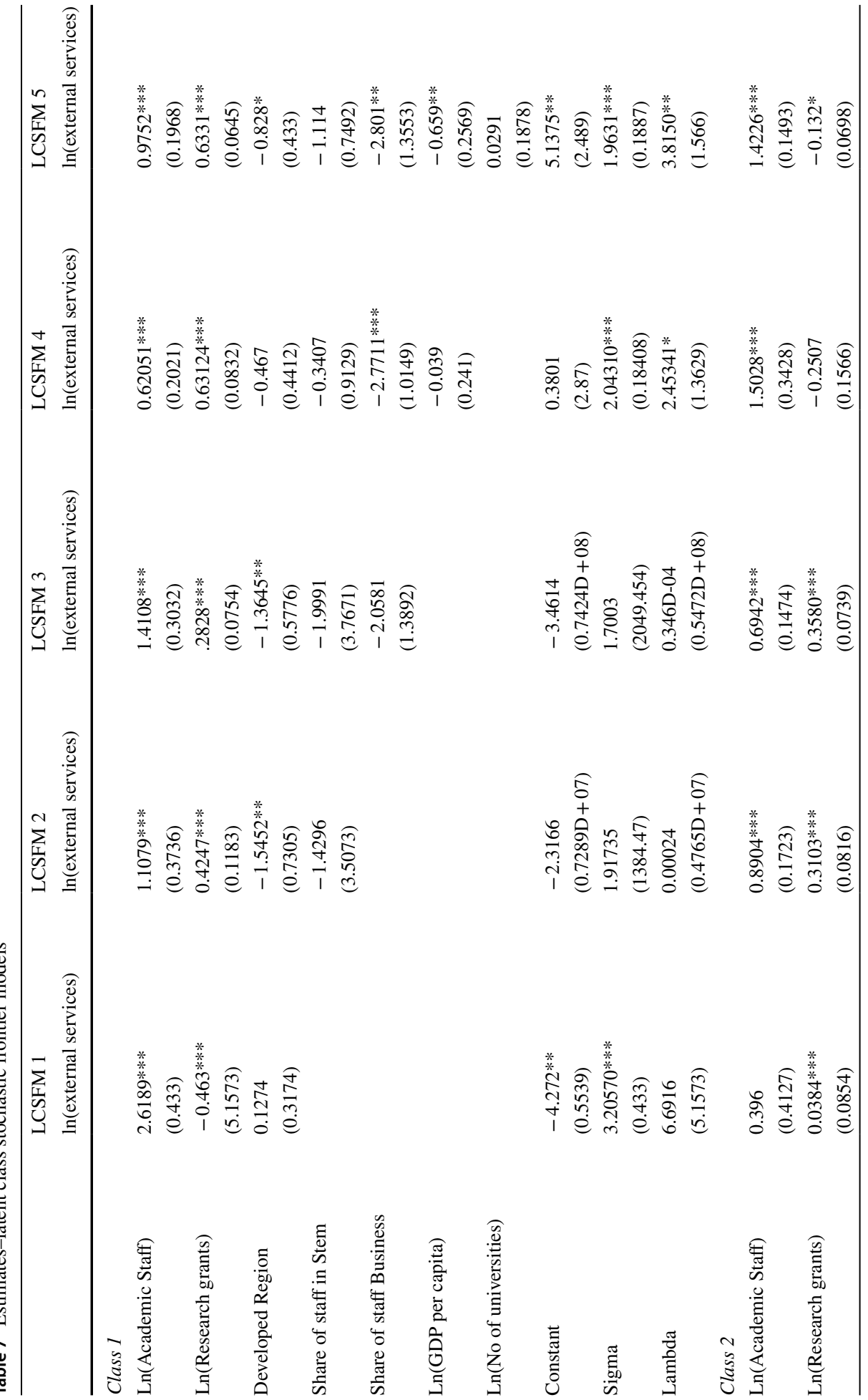




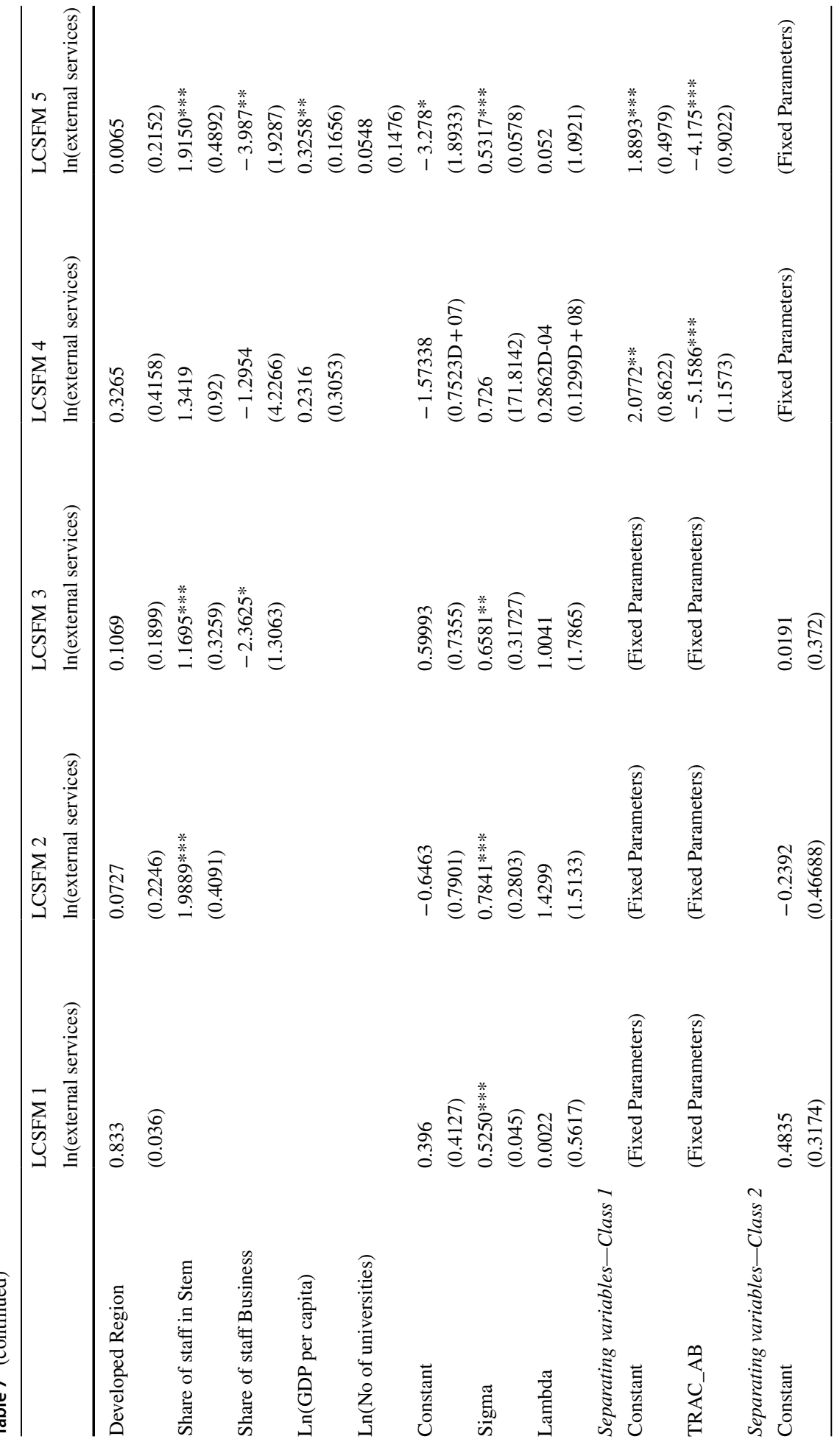




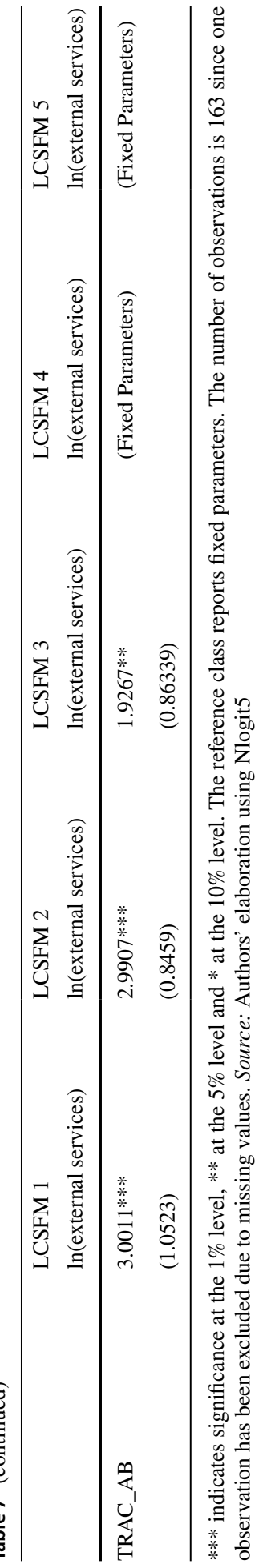


Table 8 Latent classes-descriptive statistics

\begin{tabular}{|c|c|c|c|c|}
\hline & \multicolumn{2}{|l|}{ Class 1} & \multicolumn{2}{|l|}{ Class 2} \\
\hline & Mean & Std. Dev. & Mean & Std. Dev. \\
\hline External services & 2284.03 & 3850.16 & $26,268.83$ & $32,238.71$ \\
\hline Academic staff & 601.02 & 491.17 & 1822.83 & 1557.58 \\
\hline Research grants & 4261.06 & 8305.55 & $96,418.05$ & $125,486.30$ \\
\hline Developed region & 0.7961 & 0.4049 & 0.8000 & 0.4034 \\
\hline GDP per capita & $46,730.1$ & $49,649.2$ & $58,328.3$ & $62,236.3$ \\
\hline No of universities & 7.0291 & 6.1076 & 9.1500 & 7.2342 \\
\hline Share of staff in stem & 0.1475 & 0.1548 & 0.3789 & 0.1930 \\
\hline Share of staff business & 0.1073 & 0.1233 & 0.0644 & 0.0480 \\
\hline Share of staff medicine & 0.1822 & 0.1777 & 0.2360 & 0.2062 \\
\hline AB TRAC & 0.0194 & 0.1387 & 0.9000 & 0.3025 \\
\hline Efficiency & 0.4644 & 0.2196 & 0.9803 & 0.0005 \\
\hline Observations & 103 & 60 & & \\
\hline
\end{tabular}

The descriptive statistics refer to the classes identified by LCSFM 5 (see Table 6). Source: Authors' elaboration using Stata 14

Consistent with the estimated coefficient of the separating variable, class 2 gathers the universities with the highest research grants. In detail, the mean value of income for research grants is larger than $£ 90$ million for the universities in class 2 , while it is around $£ 4$ million for class 1 institutions. Universities in class 2 are also structurally larger in terms of academic staff and tend to generate significantly higher values of external services (see the values in Table 8). This is in line with the main findings in the literature, which ascribe higher levels of academic engagement to research-intensive universities (see Laursen et al., 2011; Hewitt-Dundas, 2012; Sengupta \& Ray, 2017). Other differences between classes, even if less evident, concern the subject specialization of the academic staff. Class 2 institutions are generally more focused on STEM disciplines, while class 1 tends to gather universities that are more specialised in administration and business studies. Instead, the characteristics of the regions in which the universities are settled do not differ significantly between classes.

Based on the descriptive statistics analysed here, we can characterise class 1 universities as predominantly small institutions with a weaker research orientation, while universities in class 2 are large, research-intensive institutions, with relatively high shares of staff in STEM disciplines. This definition is confirmed by the list of universities belonging to class 2 (see Table 12 in the Appendix).

The division into the two classes effectively captures unobserved heterogeneity across the observations in our sample. The posterior probabilities for class membership reveal a very good 'fit' of data, reporting a probability of $91.88 \%$ for class 1 and $93.98 \%$ for class 2 .

We can analyse the estimates of the production functions associated with the two classes, taking as a reference the full model (LCSFM 5). The number of academic staff and the research intensity are confirmed to represent the main determinants of university-industry collaboration (see Table 7). The number of academic staff has a positive effect for both classes-with a larger effect for universities in class 2 . The variable on research grants generates, instead, an opposite effect in the two classes, with a negative coefficient associated 
with universities in class 2 and a positive one for class $1 .{ }^{10}$ The negative coefficient found for class 2 universities must be interpreted alongside the estimate on the separating variable, which defines these universities as research-intensive institutions. In other words, the value of research grants seems to represent an important determinant of UIC only for not research-oriented universities, while it is not a factor fostering external services for universities having already high levels of research grants. The results could be explained by the findings of Sengupta and Ray (2017), showing that the positive effect of research activity on academic engagement can significantly decrease when the size and the reputation of universities are particularly high. The reduction could be so relevant to generate a negative effect on research performance, as seen in the results of class- 2 institutions- having a considerably larger scale than class-1 HEIs. Indeed, the research and knowledge transfer activities are usually structurally separated when universities achieve a certain level of maturity that, in turn, is reflected by size and reputation (Sengupta \& Ray, 2017). On the contrary, for the smallest and relatively new universities, the division between research and knowledge transfer is less pronounced, and the research activities tend to be more correlated with UIC.

Class 1 universities seem to be disadvantaged if operating in 'more developed' regions (the ones receiving less European funding), while EU regional policy has no effect on the performance of institutions in class 2 . This suggests that EU regional funds are particularly effective for fostering the knowledge transfer of small universities, with low intensity of research activities. Regional GDP per capita has a statistically significant effect for the two classes, but pulls in opposite directions. The institutions in the first class are more likely to generate lower values in external services when they are located in regions with a high level of GDP per capita. This result is coherent with the negative effect of regional development, found for universities in class 1 . The GDP per capita and the variable on regional development are indeed positively correlated (see Table 4). On the contrary, universities belonging to class 2 , for which regional development has an insignificant effect, tend to establish stronger UIC when they operate in rich regions, with a high level of GDP per capita. In other words, class 1 universities seem to be channelling EU support aimed at making less-successful business more successful, while class 2 universities seem to be engaging more with businesses that are already successful.

Regarding subject specialization of academic staff, having a high percentage of researchers working in business and administration field has a negative effect on the value of the external services. This result holds for both classes, though a larger effect is found for institutions in class 2. A high specialization in STEM disciplines for universities in class 2 has a positive impact on business interaction, but this variable is not significant in the case of class 1 institutions. Finally, the number of universities in the region-included here to capture competition effects-does not represent a relevant factor for the knowledge transfer of higher education institutions. This seems to suggest that the competition in contract research among universities does not strictly depend on the geographical distance, but HEIs are more likely to compete on other factors (such as research performance). Indeed, as found by Laursen et al. (2011), businesses tend to prefer research quality over geographical proximity of the university.

The two classes are structurally different also in terms of technical efficiency. The mean level of efficiency is $46.44 \%$ for class 1 , and $98.03 \%$ for class 2 (see Table 8 ). The

\footnotetext{
10 The distribution of research grants of class-2 universities has a lower variance than that of the other group. This may affect the standard deviations of research grants in the results of Table 7 .
} 


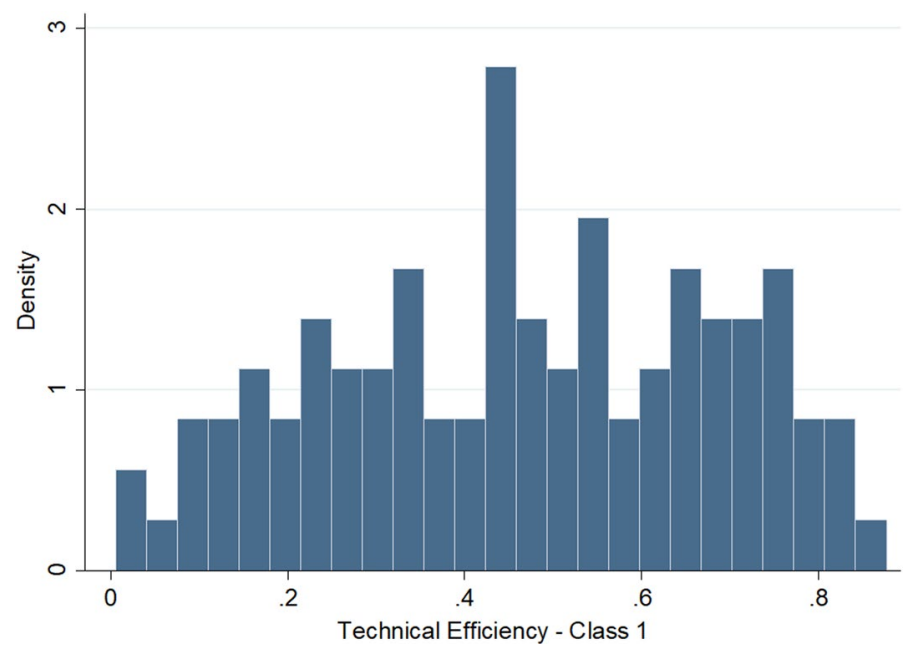

Fig. 5 Efficiency scores - Class 1 in LCSFM 5. Source: Authors' elaboration using Stata 14

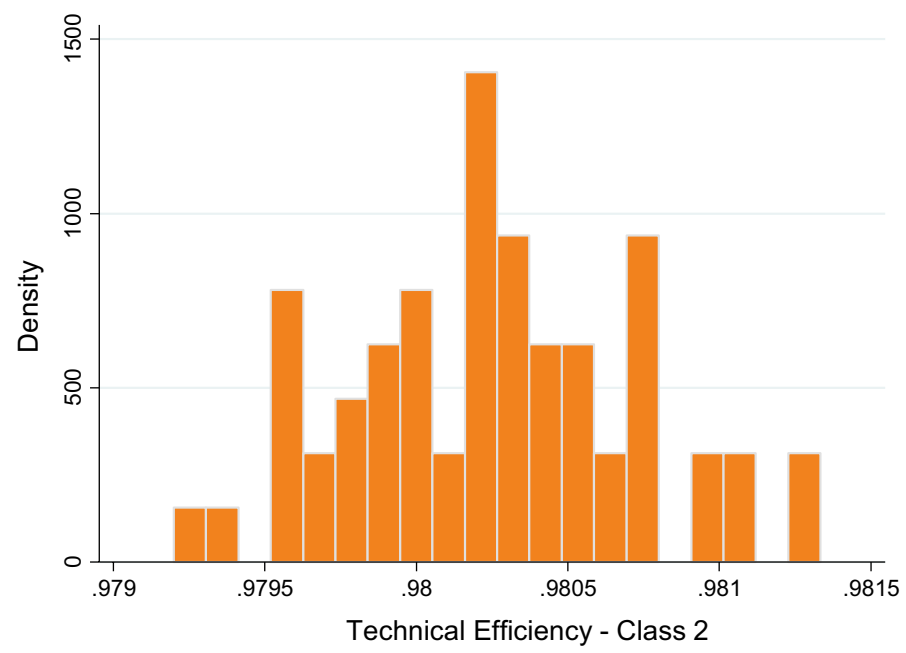

Fig. 6 Efficiency scores - Class 2 in LCSFM 5. Source: Authors' elaboration using Stata 14

distribution of the efficiency scores is analysed by the histograms in Fig. 5 and 6 . The scores estimated for universities in class 2 (see Fig. 4) report high levels of efficiency (very close to 1) with limited variability among institutions. On the other hand, universities in class 1-representing the more numerous group-report scores varying significantly between HEIs, moving in an interval from zero to 0.87 . Even if the efficiency scores are not properly comparable between classes, the results seem to suggest that class 1 can also include inefficient universities, while class 2 institutions seem to be equally efficient in providing external services to industry and companies. These results tend to confirm what has been found for licencing activities by Anderson et al. (2007), with research-intensive universities 


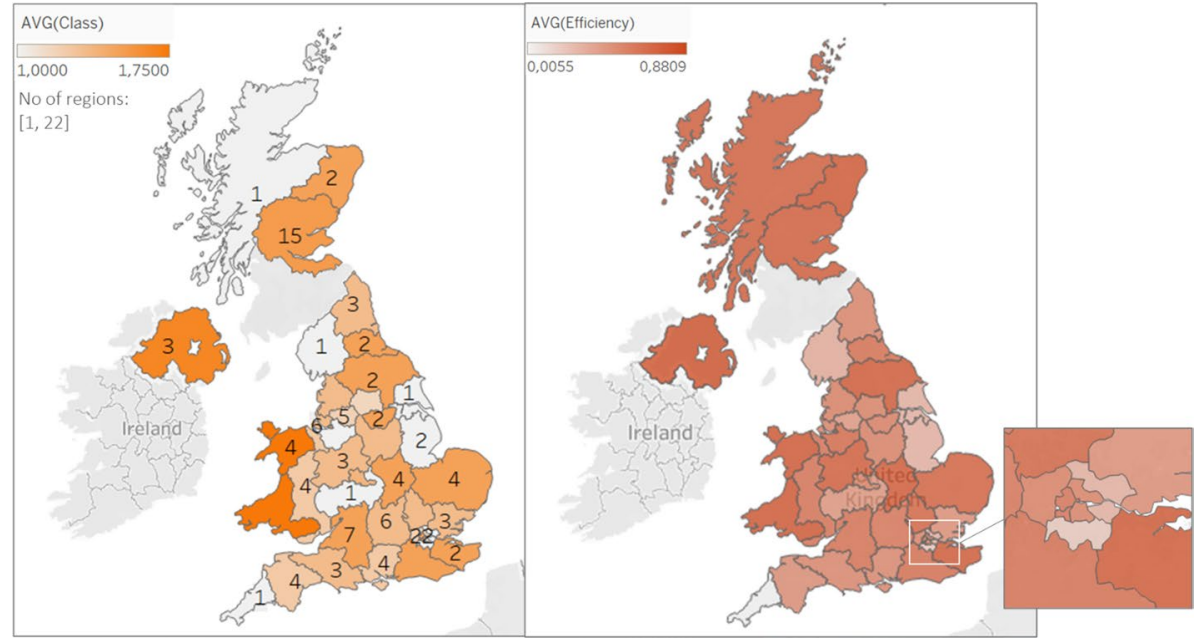

Fig. 7 Average efficiency scores and average class membership per region. Note: The map on the left side reports the average of class membership (colour) over regions, found for LCSFM 5, and the respective number of universities (number). The map on the right side reports the average of efficiency scores over regions. Source: Authors' elaboration using Tableau Public

able to manage knowledge transfer more efficiently than others. Indeed, firms usually prefer to collaborate with top research universities, which can largely contribute to innovation collaborations (Laursen et al., 2011). Thus, research-intensive institutions are likely to manage a larger number of interactions with industry and to achieve greater experience in the field. In this sense, the results of the paper suggest the existence of economies of scope and scale. Moreover, class-2 universities are characterised by larger funding (see Table 8), which may support UIC organisational activities and, in turn, positively impact on efficiency in managing interactions with industry.

Finally, we analysed the geographical distribution of the universities' efficiency. The maps in Fig. 7 represent the average level of efficiency and the mean value of class membership over regions. The most efficient region is Northern Ireland, which reports an average score of $88.1 \%$. Three universities operate in this region, one belonging to class 1 and two belonging to class 2. High levels of efficiency are also reported by the region of West Wales and the of Valleys and North Eastern Scotland, respectively with $84.8 \%$ and 84,7\% of efficiency. On the contrary, the most inefficient region is Cornwall and Isles of Scilly, in which only one university operates, belonging to class 1 , and presenting an efficiency score of $0.5 \%$.

\section{Conclusion}

Engagement has become a keyword for universities in recent years. Yet the extent to which universities engage with business varies considerably. We have shown in this paper that this variation is systematic, with certain key variables-notably the size of the university and its subject mix-being important determinants of the extent of engagement activity. But at the same time it is clear that different universities respond differently to the challenge of engagement, and the evidence suggests the presence of unobserved heterogeneity across institutions. 
The findings suggest the existence of different models of UIC based on the characteristics of higher education institutions. This result is particularly relevant since, when we assume the existence of a common model of engagement across universities, the empirical analyses lead to results that only partially explain the relationships between UIC and its determinants (see results in "Regressions and stochastic frontier model estimates" section). In the same way, the estimates of efficiency scores can lead to misleading results when structural differences between universities are not taken into account. We controlled for heterogeneity across institutions by using a latent class stochastic frontier model, which represents a novel methodological application in the study of UIC efficiency. In particular, the LCSFM results suggest the existence of two classes of universities that respond differently to the determinants of UIC. While the level of regional development ${ }^{11}$ and an institutional focus on STEM subjects ${ }^{12}$ both positively influence engagement for one group of universities (those having a concentration of research-intensive institutions), the same is not true of the other group. These results point to the importance of institutional factors as determinants of UIC, a finding that contrasts with the extant literature that ascribes a greater impact of individual characteristics-especially for contract research (D'Este \& Patel, 2007; Thune et al., 2016; Zhao et al., 2020). However, the impacts of university-level factors can be different between types of institutions. For this reason, effective policies, aimed at fostering the value of knowledge transfer, should take into account the heterogeneity of HEIs and address different actions for research-intensive universities and non-research-intensive universities.

Another important result of the paper is that the efficiency with which institutions convert their resources into business engagement outputs-particularly the less research-intensive institutions that comprise latent class 1 -varies considerably across institutions. ${ }^{13}$ From a policy perspective, our findings seem to suggest that institutional-level policies can have a relevant role in enhancing the level of efficiencies of small and non-research-intensive universities. On the other hand, the institutional characteristics are not likely to affect the efficiency in UIC activities of large and research-intensive universities, which show homogeneous levels of efficiency regardless of their differences.

Within each of the latent classes identified by our analysis, there exists considerable variation in the level of engagement activity. Institutions in latent class 1 (the less researchintensive group) that are, within their peer group, relatively research-active, tend also to have higher levels of engagement (cf. Hewitt-Dundas, 2012). Besides, the size of HEIs strongly influence the extend of consultancy and contract research of all the universities analysed, but the effect is larger for class 2 than for class 1 . The positive relationship between university scale and engagement may be related to the high level of physical and financial resources available for large-scale universities (Ho et al., 2014).

All these findings are based on the analysis of the external services of universities, representing an important novelty of the paper. While the literature focuses mainly on patents and licences, the measure of external services allows a more direct indicator of knowledge transfer activities of universities that focuses on more diffuse, even if less studied, forms of UIC. Patents measure the most tangible and commercial outputs of academic research, but they represent the smallest part of overall interactions with industry (Perkmann et al., 2011). In addition, intellectual property is structurally different from more collaborative

\footnotetext{
11 See D'Este et al. (2013), Gunasekane (2006), Laranja et al. (2008), Huggins et al. (2008).

12 This aligns with the findings of Thursby and Kemp (2002) and Bozeman and Gaughan (2007).

13 The results are in line with the findings of Anderson et al. (2007), who detected high levels of efficiency associated with the knowledge transfer of the leading universities.
} 
forms of knowledge transfer and are subject to partially different dynamics (Perkmann et al., 2013). For example, IP often excludes knowledge transfer in social science and humanities, which are more likely to be transferred through contracts for external services (Perkmann et al., 2013; Ramos-Vielba et al., 2010). The present paper thus expands our knowledge on the efficiency of UIC, by including evidence on the contract research and consultancy services provided by universities to industry.

A limitation of the paper is that, by necessity, it focuses on the characteristics of the higher education institutions at the expense of those of businesses with whom these institutions engage. Unfortunately the available data do not provide detail of the latter. However, it is clearly the case that engagement is a two way street, and matches between academic and industrial partners require synergy between both sides. Nevertheless, we believe that we have made important insights into the determinants of such activity on the higher education institutions' side.

Finally, the paper provides evidence useful for managerial and policy purposes. The results here presented inform universities and policymakers on the most relevant factors influencing the university-industry collaboration and identify the most efficient higher education institutions that can serve as exemplars in providing external services to companies. In this way, the insight provided by the paper may help policymakers to define effective actions to foster the knowledge transfer activities of universities.

\section{Appendix}

\section{Robustness check-London as one aggregated region}

In Table 9, we repeated the LCSFM analyses by considering all the universities in London as belonging to one region, instead of dividing them into the two areas defined by NUTS classification (i.e. West Inner London - UKI3 and East Inner London - UKI4). Accordingly, the values of the variables at regional level have been modified for all the universities operating in London. In particular, the number of universities has increased to 29, which is the sum of the institutions in West Inner London (with 22 universities) and in East Inner London (with 7 universities). Besides, the GDP per capita of the aggregated region has been calculated as the mean between the values for the two NUTS, weighted for the respective level of population. The aggregation instead does not affect the variable of regional development since both UKI3 and UKI4 are classified as 'more developed'. Therefore, Table 9 reports the results of the latent class stochastic frontier models that include the GDP per capita and on the number of universities (i.e. LCSFM 4 and LCSFM 5).

The results of LCSFM 5-V2 are similar to the ones found by considering the two NUTS separately (see LCSFM 5 in Table 6). The main difference is that the effects of regional development and the GDP per capita are no more statistically significant for class 1 universities. This discrepancy could be due to the decrease in the variance of GDP per capita-that is constant for all the 29 universities in London. Besides, the division of the universities into the two classes is similar to the results of LCSFM 5. Class 2 gathers 59 research-intensive universities, while class 1 includes 109 universities that are less likely to be classified as type A or B of TRAC definition. In terms of technical efficiency, the average value for class 1 universities is 0.4597 , which is almost unvaried compared to the results in the main analyses (see Table 7). Instead, the mean of efficiency for class 2 universities is 0.7423 and is significantly lower than the one that has been found in Table 7 . 
Table 9 Estimates considering London as one aggregated region-Latent class stochastic frontier models

\begin{tabular}{|c|c|c|}
\hline & $\begin{array}{l}\text { LCSFM 4-V2 } \\
\ln (\text { external services) }\end{array}$ & $\begin{array}{l}\text { LCSFM 5-V2 } \\
\ln \text { (external services) }\end{array}$ \\
\hline \multicolumn{3}{|l|}{ Class 1} \\
\hline $\operatorname{Ln}($ Academic staff $)$ & $\begin{array}{l}1.2670 * * * \\
(0.3542)\end{array}$ & $\begin{array}{l}0.6403 * * * \\
(0.1672)\end{array}$ \\
\hline Ln(Research grants) & $\begin{array}{l}0.4327 * * * \\
(0.0992)\end{array}$ & $\begin{array}{l}0.6451 * * * \\
(0.0665)\end{array}$ \\
\hline Developed region & $\begin{array}{l}-0.3098 \\
(0.4375)\end{array}$ & $\begin{array}{l}-0.4631 \\
(0.3780)\end{array}$ \\
\hline Share of staff in Stem & $\begin{array}{l}0.7970 \\
(0.8133)\end{array}$ & $\begin{array}{l}0.5118 \\
(0.6621)\end{array}$ \\
\hline Share of staff business & $\begin{array}{l}3.9852 \\
(4.7320)\end{array}$ & $\begin{array}{l}-2.8094 * * * \\
(1.0238)\end{array}$ \\
\hline Ln(GDP per capita) & $\begin{array}{l}-0.5422 \\
(0.3420)\end{array}$ & $\begin{array}{l}-0.4982 \\
(0.5158)\end{array}$ \\
\hline Ln(No of universities) & & $\begin{array}{l}0.0439 \\
(0.2817)\end{array}$ \\
\hline Constant & $\begin{array}{l}2.0891 \\
(2.8495)\end{array}$ & $\begin{array}{l}4.9207 \\
(5.2057)\end{array}$ \\
\hline Sigma & $\begin{array}{l}1.9114 * * * \\
(0.2125)\end{array}$ & $\begin{array}{l}2.0482 * * * \\
(0.1501)\end{array}$ \\
\hline Lambda & $\begin{array}{l}6.4681 \\
(4.3080)\end{array}$ & $\begin{array}{l}3.6084 * * * \\
(1.5335)\end{array}$ \\
\hline \multicolumn{3}{|l|}{ Class 2} \\
\hline $\operatorname{Ln}($ Academic staff) & $\begin{array}{l}0.6866^{* * *} \\
(0.1182)\end{array}$ & $\begin{array}{l}1.7538 * * * \\
(0.1547)\end{array}$ \\
\hline $\mathrm{Ln}$ (Research grants) & $\begin{array}{l}0.2573 * * * \\
(0.0534)\end{array}$ & $\begin{array}{l}-0.2547 * * * \\
(0.0564)\end{array}$ \\
\hline Developed region & $\begin{array}{l}-0.1214 \\
(0.2450)\end{array}$ & $\begin{array}{l}-0.0393 \\
(0.2247)\end{array}$ \\
\hline Share of staff in stem & $\begin{array}{l}1.1108 * * * \\
(0.5170)\end{array}$ & $\begin{array}{l}1.9611 * * * \\
(0.4932)\end{array}$ \\
\hline Share of staff business & $\begin{array}{l}-7.4798 * * * \\
(0.6855)\end{array}$ & $\begin{array}{l}-2.1246 \\
(1.7439)\end{array}$ \\
\hline Ln(GDP per capita) & $\begin{array}{l}0.208 \\
(0.2125)\end{array}$ & $\begin{array}{l}0.8297 * * * \\
(0.2743)\end{array}$ \\
\hline $\mathrm{Ln}$ (No of universities) & & $\begin{array}{l}0.0523 \\
(0.1474)\end{array}$ \\
\hline Constant & $\begin{array}{l}-0.1634 \\
(2.3691)\end{array}$ & $\begin{array}{l}-9.06053 * * * \\
(3.11743)\end{array}$ \\
\hline Sigma & $\begin{array}{l}0.7391 * * * \\
(0.0626)\end{array}$ & $\begin{array}{l}0.6623 * * * \\
(0.1673)\end{array}$ \\
\hline Lambda & $\begin{array}{l}0.0275 \\
(0.9463)\end{array}$ & $\begin{array}{l}2.7705 \\
(2.5229)\end{array}$ \\
\hline Separating variables-Class 1 & & \\
\hline
\end{tabular}


Table 9 (continued)

\begin{tabular}{lll}
\hline & $\begin{array}{l}\text { LCSFM 4-V2 } \\
\ln (\text { external services) }\end{array}$ & $\begin{array}{l}\text { LCSFM 5-V2 } \\
\ln (\text { external services) }\end{array}$ \\
\hline Constant & (Fixed Parameters) & $2.7273 * * *$ \\
& (Fixed Parameters) & $(0.7550)$ \\
TRAC_AB & (Fixed Parameters) & $-1.1118^{* * *}$ \\
Separating variables_Class 2 & (Fixed Parameters) & $(0.9665)$ \\
Constant & & \\
TRAC_AB & $-0.5120 * *$ & (Fixed Parameters) \\
& $(0.3453)$ & (Fixed Parameters) \\
& $3.2349 * * *$ & (Fixed Parameters) \\
& $(1.1889)$ & (Fixed Parameters) \\
\hline
\end{tabular}

$* * *$ indicates significance at the $1 \%$ level, $* *$ at the $5 \%$ level and * at the $10 \%$ level. The reference class reports fixed parameters. The number of observations is 163 since one observation has been excluded due to missing values. Source: Authors' elaboration using Nlogit5

Table 10 Top 15 efficiency scores-model SFA 7

\begin{tabular}{llc}
\hline University & Technical efficiency & Rank \\
\hline Conservatoire for dance and drama & 0.83504 & 1 \\
The liverpool institute for performing arts & 0.748732 & 2 \\
University of the highlands and Islands & 0.693066 & 3 \\
Liverpool school of tropical medicine & 0.675644 & 4 \\
Leeds beckett university & 0.659401 & 5 \\
the university of northampton & 0.644862 & 6 \\
Royal college of art & 0.633708 & 7 \\
The royal central school of speech and drama & 0.623504 & 8 \\
AECC university college & 0.623209 & 9 \\
Cardiff metropolitan university & 0.621609 & 10 \\
SRUC & 0.619094 & 11 \\
Glasgow school of art & 0.604797 & 12 \\
The university of greenwich & 0.601883 & 13 \\
Royal agricultural university & 0.593445 & 14 \\
London school of economics and political science & 0.590275 & 15 \\
\hline
\end{tabular}

Source: Authors' elaboration

The results of LCSF 4-V2 do not vary considerably from the ones reported for the same model in Table 6 (see LCSF 4). The main differences are in the coefficients of the share of staff in STEM, for class 1 universities, and research grants, for class 2 universities. In both cases, we found significant and positive effects that were not detected from the results reported in Table 6.

\section{Efficiency scores of stochastic frontier analysis}

Table 10 reports the efficiency scores associated with SFA7 in Table 7. 


\section{Setting the number of classes}

Table 11 reports the Bayesian Information Criterion and Akaike Information Criterion statistics associated with a number of classes from 1 to 5 . The preferred model is the model with two classes since it reports the lowest value of BIC. The model with two classes also shows a low value of AIC, which is very close to the lowest value of AIC, reported for the model with three classes. Moreover, selecting the number of classes equal to two, instead of three, we can obtain more interpretable results.

Table 11 BIC and AIC statistics

\begin{tabular}{lll}
\hline No of classes & BIC & AIC \\
\hline 1 & 618.95 & 588.01 \\
2 & 576.75 & 508.69 \\
3 & 607.40 & 502.21 \\
4 & 744.14 & 601.82 \\
5 & 749.71 & 570.27 \\
\hline
\end{tabular}

$\mathrm{AIC}=$ Akaike Information Criterion; $\mathrm{BIC}=$ Bayesian Information Criterion. Source: Authors' elaboration using Nlogit5

\section{List of class 1 and class 2 universities}

Table 12 reports the complete list of universities belonging to class 1 and class 2, according to the results for LCSFM 5. 


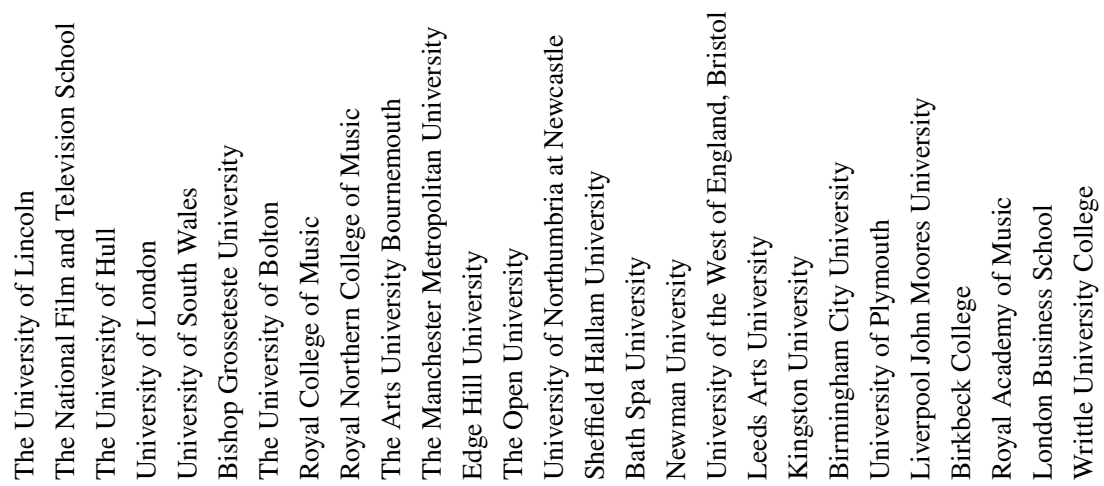

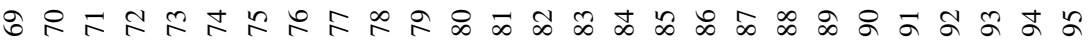

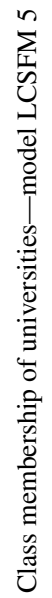

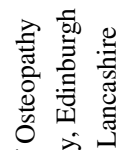

تृّే

苍

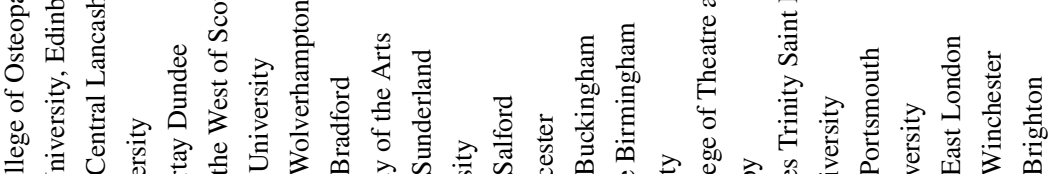

苛

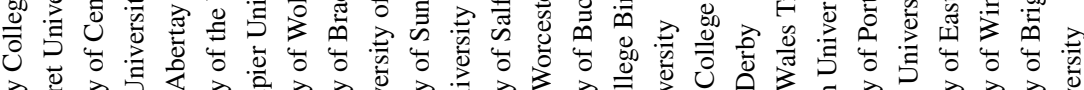

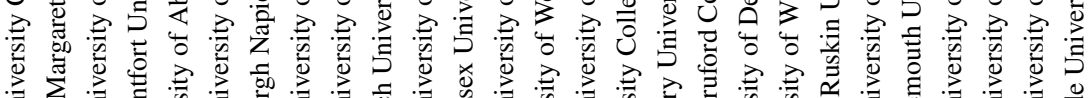

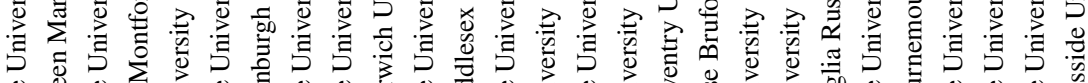
Q

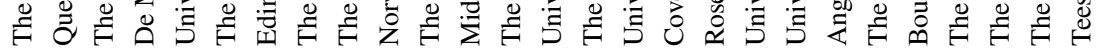

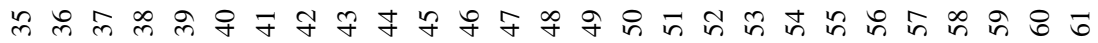

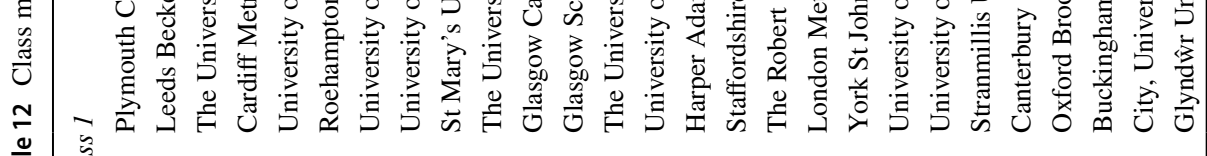

完 

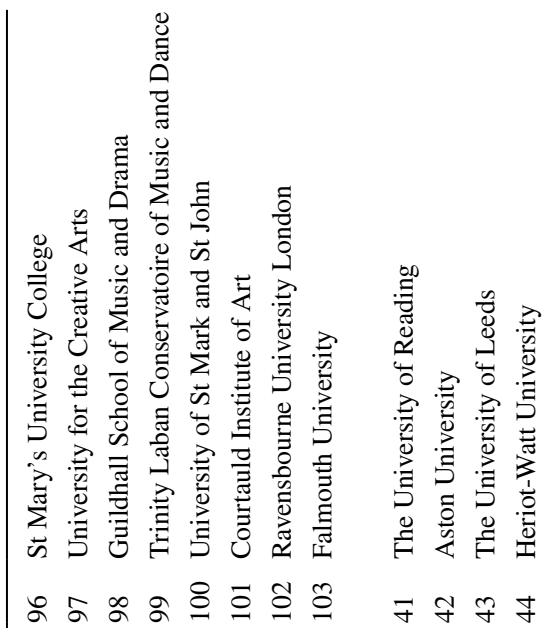

告

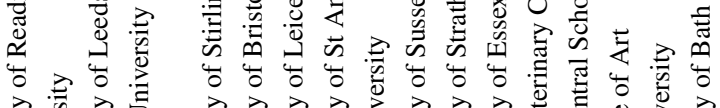

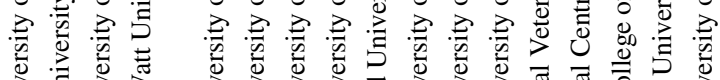

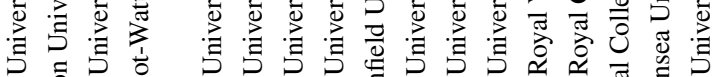

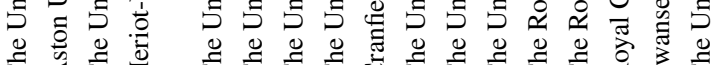

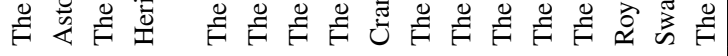

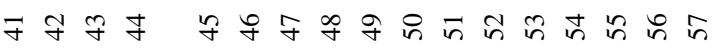

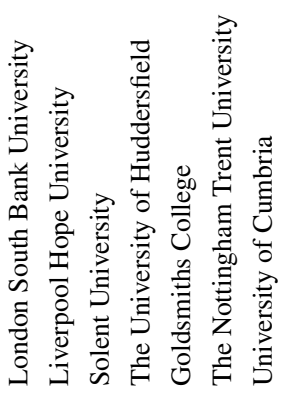
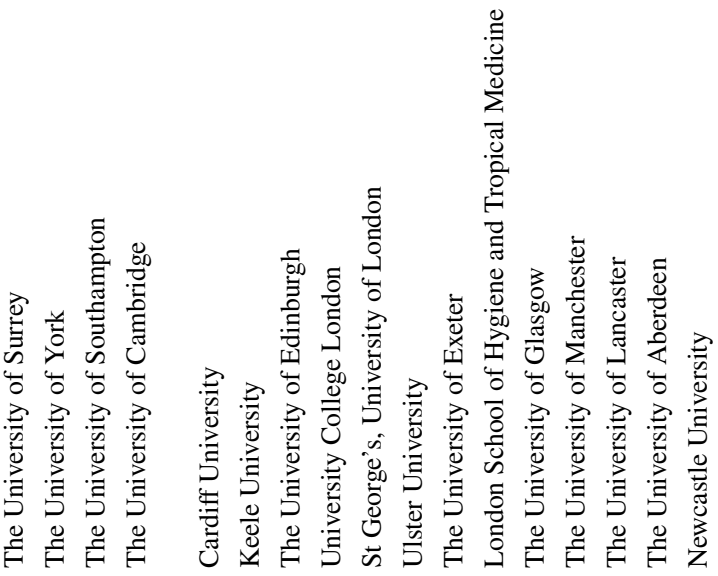

ชู

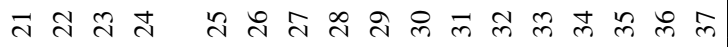
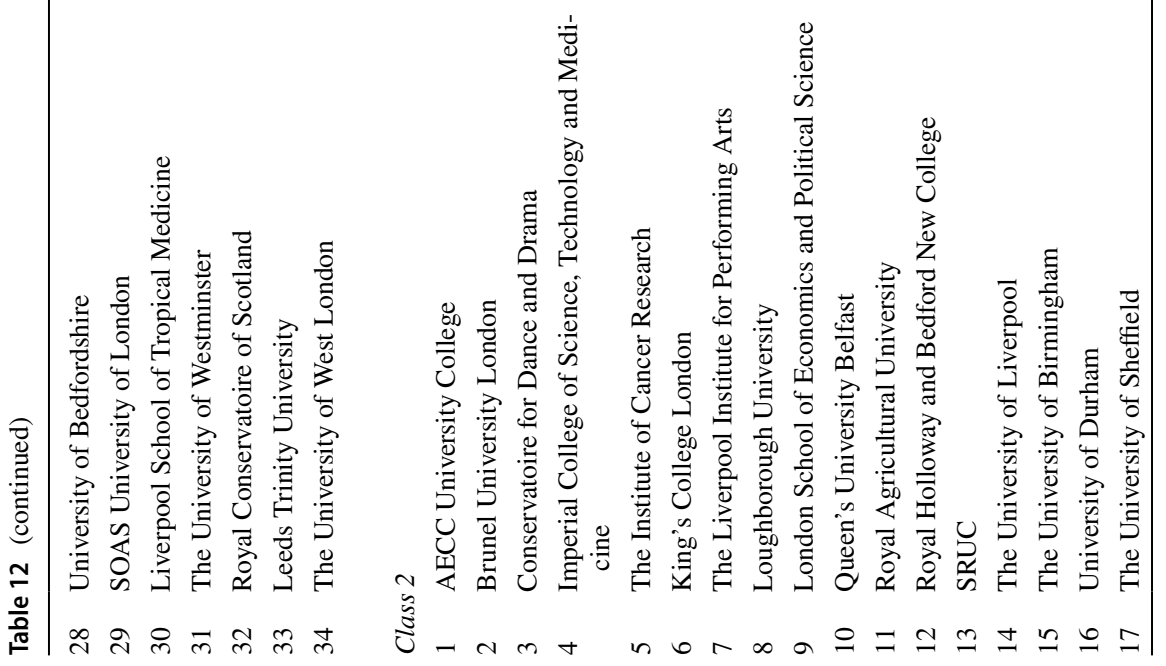


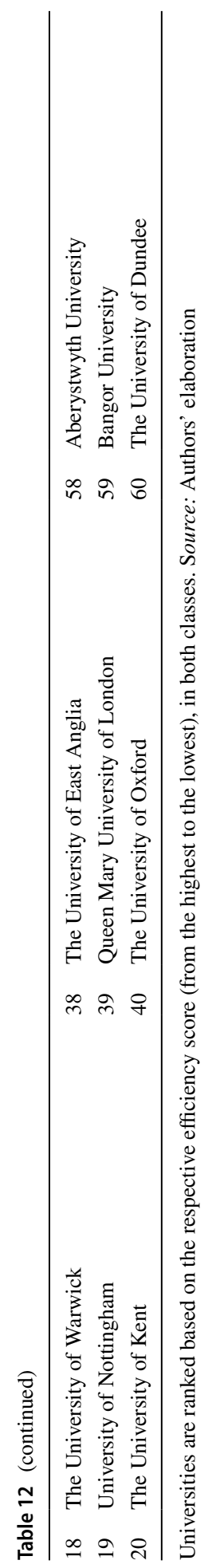


Funding Open access funding provided by Politecnico di Milano within the CRUI-CARE Agreement.

Open Access This article is licensed under a Creative Commons Attribution 4.0 International License, which permits use, sharing, adaptation, distribution and reproduction in any medium or format, as long as you give appropriate credit to the original author(s) and the source, provide a link to the Creative Commons licence, and indicate if changes were made. The images or other third party material in this article are included in the article's Creative Commons licence, unless indicated otherwise in a credit line to the material. If material is not included in the article's Creative Commons licence and your intended use is not permitted by statutory regulation or exceeds the permitted use, you will need to obtain permission directly from the copyright holder. To view a copy of this licence, visit http://creativecommons.org/licenses/by/4.0/.

\section{References}

Agasisti, T., \& Gralka, S. (2019). The transient and persistent efficiency of Italian and German universities: A stochastic frontier analysis. Applied Economics, 51, 1-19.

Agasisti, T., \& Johnes, G. (2015). Efficiency, costs, rankings and heterogeneity: The case of US higher education. Studies in Higher Education, 40(1), 60-82.

Agrawal, A., \& Henderson, R. (2002). Putting patents in context: Exploring knowledge transfer from MIT. Management science, 48(1), 44-60.

Aigner, D., Lovell, C. K., \& Schmidt, P. (1977). Formulation and estimation of stochastic frontier production function models. Journal of Econometrics, 6(1), 21-37.

Al-Tabbaa, O., \& Ankrah, S. (2016). Social capital to facilitate 'engineered'university-industry collaboration for technology transfer: A dynamic perspective. Technological Forecasting and Social Change, $104,1-15$.

Anderson, T. R., Daim, T. U., \& Lavoie, F. F. (2007). Measuring the efficiency of university technology transfer. Technovation, 27(5), 306-318.

Ankrah, S. N., Burgess, T. F., Grimshaw, P., \& Shaw, N. E. (2013). Asking both university and industry actors about their engagement in knowledge transfer: What single-group studies of motives omit. Technovation, 33(2-3), 50-65.

Ankrah, S., \& Al-Tabbaa, O. (2015). Universities-industry collaboration: A systematic review. Scandinavian Journal of Management, 31(3), 387-408.

Azagra-Caro, J. M., Archontakis, F., Gutiérrez-Gracia, A., \& Fernández-de-Lucio, I. (2006). Faculty support for the objectives of university-industry relations versus degree of R\&D cooperation: The importance of regional absorptive capacity. Research Policy, 35(1), 37-55.

Battese, G. E., Rao, D. P., \& O'donnell, C. J. (2004). A metafrontier production function for estimation of technical efficiencies and technology gaps for firms operating under different technologies. Journal of Productivity Analysis, 21(1), 91-103.

Bekkers, R., \& BodasFreitas, I. M. B. (2008). Analysing knowledge transfer channels between universities and industry: To what degree do sectors also matter? Research Policy, 37(10), 1837-1853.

Bonaccorsi, A., \& Piccaluga, A. (1994). A theoretical framework for the evaluation of university-industry relationships. $R \& D$ Management, 24(3), 229-247.

Boutifour, Z., Saad, M., \& Guermat, C. (2015). An investigation into the key determinants of universityindustry links in Algeria. International Journal of Technology Management \& Sustainable Development, 14(2), 93-111.

Bozeman, B., \& Gaughan, M. (2007). Impacts of grants and contracts on academic researchers' interactions with industry. Research Policy, 36(5), 694-707.

D'Este, P., \& Patel, P. (2007). University-industry linkages in the UK: What are the factors underlying the variety of interactions with industry? Research Policy, 36(9), 1295-1313.

D'Este, P., \& Perkmann, M. (2011). Why do academics engage with industry? The entrepreneurial university and individual motivations. The Journal of Technology Transfer, 36(3), 316-339.

D'Este, P., Guy, F., \& Iammarino, S. (2013). Shaping the formation of university-industry research collaborations: What type of proximity does really matter? Journal of Economic Geography, 13(4), 537-558.

Eurostat (2020). Patent applications to the European patent office (EPO) by priority year [Data file]. Retrieved from: https://ec.europa.eu/eurostat/databrowser/view/tsc00009/default/table?lang=en. 
Fernández-Esquinas, M., Pinto, H., Yruela, M. P., \& Pereira, T. S. (2016). Tracing the flows of knowledge transfer: Latent dimensions and determinants of university-industry interactions in peripheral innovation systems. Technological Forecasting and Social Change, 113, 266-279.

Goldfarb, B., \& Henrekson, M. (2003). Bottom-up versus top-down policies towards the commercialization of university intellectual property. Research Policy, 32(4), 639-658.

Grassmuck, K. (1991). Gatorade Brings U. of Florida \$17-Million and 5 Court Actions. Chronicle of Higher Education, 37(39), A25-A26.

Greene, W. (2005). Reconsidering heterogeneity in panel data estimators of the stochastic frontier model. Journal of Econometrics, 126(2), 269-303.

Gulbrandsen, M., \& Smeby, J. C. (2005). Industry funding and university professors' research performance. Research Policy, 34(6), 932-950.

Gunasekara, C. (2006). Reframing the role of universities in the development of regional innovation systems. The Journal of Technology Transfer, 31(1), 101-113.

Haeussler, C., \& Colyvas, J. A. (2011). Breaking the ivory tower: Academic entrepreneurship in the life sciences in UK and Germany. Research Policy, 40(1), 41-54.

Hewitt-Dundas, N. (2012). Research intensity and knowledge transfer activity in UK universities. Research Policy, 41(2), 262-275.

Ho, M. H. C., Liu, J. S., Lu, W. M., \& Huang, C. C. (2014). A new perspective to explore the technology transfer efficiencies in US universities. The Journal of Technology Transfer, 39(2), 247-275.

Huggins, R., Johnston, A., \& Steffenson, R. (2008). Universities, knowledge networks and regional policy. Cambridge Journal of Regions, Economy and Society, 1(2), 321-340.

Johnes, G. \& Johnes, J. (2013) Efficiency in the higher education sector: a technical exploration, Department for Business Innovation and Skills Research Paper 113, http://bit.ly/2PaEkRj.

Johnes, G., \& Johnes, J. (2009). Higher education institutions' costs and efficiency: Taking the decomposition a further step. Economics of Education Review, 28(1), 107-113.

Johnes, G., \& Salas-Velasco, M. (2007). The determinants of costs and efficiencies where producers are heterogeneous: The case of Spanish universities. Economics Bulletin, 4(15), 1-9.

Johnes, G., Camanho, A. S., \& Portela, M. S. (2008). Assessing efficiency of portuguese universities through parametric and non-parametric methods. Portuguese Journal of Management Studies, 13(1), 39-66.

Landry, R., Amara, N., \& Ouimet, M. (2007). Determinants of knowledge transfer: Evidence from Canadian university researchers in natural sciences and engineering. The Journal of Technology Transfer, 32(6), 561-592.

Laranja, M., Uyarra, E., \& Flanagan, K. (2008). Policies for science, technology and innovation: Translating rationales into regional policies in a multi-level setting. Research Policy, 37(5), 823-835.

Laureti, T., Secondi, L., \& Biggeri, L. (2014). Measuring the efficiency of teaching activities in Italian universities: An information theoretic approach. Economics of Education Review, 42, 147-164.

Laursen, K., Reichstein, T., \& Salter, A. (2011). Exploring the effect of geographical proximity and university quality on university-industry collaboration in the United Kingdom. Regional Studies, 45(4), 507-523.

Maudos, J., Pastor, J. M., \& Perez, F. (2002). Competition and efficiency in the Spanish banking sector: The importance of specialization. Applied Financial Economics, 12(7), 505-516.

Mueller, P. (2006). Exploring the knowledge filter: How entrepreneurship and university-industry relationships drive economic growth. Research Policy, 35(10), 1499-1508.

Newman, C., \& Matthews, A. (2006). The productivity performance of Irish dairy farms 1984-2000: A multiple output distance function approach. Journal of Productivity Analysis, 26(2), 191-205.

OECD. (2019). University-industry collaboration: New evidence and policy options. OECD Publishing, Paris. https://doi.org/10.1787/e9c1e648-en

Orea, L., \& Kumbhakar, S. C. (2004). Efficiency measurement using a latent class stochastic frontier model. Empirical Economics, 29(1), 169-183.

O'shea, R. P., Allen, T. J., Chevalier, A., \& Roche, F. (2005). Entrepreneurial orientation, technology transfer and spinoff performance of US universities. Research Policy, 34(7), 994-1009.

Perkmann, M., King, Z., \& Pavelin, S. (2011). Engaging excellence? Effects of faculty quality on university engagement with industry. Research Policy, 40(4), 539-552.

Perkmann, M., Tartari, V., McKelvey, M., Autio, E., Broström, A., D’Este, P., Fini, R., Geuna, A., Grimaldi, R., Hughes, A., Krabel, S., Kitson, M., Llerena, P., Lissoni, F., Salter, A., \& Sobrero, M. (2013). Academic engagement and commercialisation: A review of the literature on university-industry relations. Research Policy, 42(2), 423-442.

Ramos-Vielba, I., Fernández-Esquinas, M., \& Espinosa-de-los-Monteros, E. (2010). Measuring universityindustry collaboration in a regional innovation system. Scientometrics, 84(3), 649-667. 
Roessner, J. D., \& Bean, A. S. (1993). Industry interaction with federal labs pays off. Research-Technology Management, 36(5), 38-40.

Santoro, M. D., \& Gopalakrishnan, S. (2000). The institutionalization of knowledge transfer activities within industry-university collaborative ventures. Journal of Engineering and Technology Management, 17(3-4), 299-319.

Sauer, J., \& Paul, C. J. M. (2013). The empirical identification of heterogeneous technologies and technical change. Applied Economics, 45(11), 1461-1479.

Sengupta, A., \& Ray, A. S. (2017). University research and knowledge transfer: A dynamic view of ambidexterity in british universities. Research Policy, 46(5), 881-897.

Siegel, D. S., Waldman, D., \& Link, A. (2003). Assessing the impact of organizational practices on the relative productivity of university technology transfer offices: An exploratory study. Research Policy, 32(1), 27-48.

Thune, T., Reymert, I., Gulbrandsen, M., \& Olaf Aamodt, P. (2016). Universities and external engagement activities: Particular profiles for particular universities? Science and Public Policy, 43(6), 774-786.

Thursby, J. G., \& Kemp, S. (2002). Growth and productive efficiency of university intellectual property licensing. Research Policy, 31(1), 109-124.

Van Looy, B., Ranga, M., Callaert, J., Debackere, K., \& Zimmermann, E. (2004). Combining entrepreneurial and scientific performance in academia: towards a compounded and reciprocal Matthew-effect? Research Policy, 33(3), 425-441.

Zhao, Z., Broström, A., \& Cai, J. (2020). Promoting academic engagement: University context and individual characteristics. The Journal of Technology Transfer, 45(1), 304-337. 